\title{
Tumor suppressor miR-1 inhibits tumor growth and metastasis by simultaneously targeting multiple genes
}

\author{
Cuilian Liu' ${ }^{1}$, Song Zhang ${ }^{1}$, Qizhi Wang ${ }^{2}$ and Xiaobo Zhang ${ }^{1}$ \\ ${ }^{1}$ College of Life Sciences and Laboratory for Marine Biology and Biotechnology of Qingdao National Laboratory for Marine \\ Science and Technology, Zhejiang University, Hangzhou 310058, The People's Republic of China \\ ${ }^{2}$ Department of Gastroenterology, The First Affiliated Hospital of Bengbu Medical College, Bengbu 233030, The People's \\ Republic of China
}

Correspondence to: Xiaobo Zhang, email: zxb0812@zju.edu.cn

Keywords: miR-1, target gene, tumor growth, metastasis

Abbreviations: TWF1: twinfilin actin binding protein 1; TMSB4X: thymosin beta 4, X-linked; WASF2: WAS protein family member 2; CNN3: calponin 3; CORO1C: coronin 1C

Received: October 15, $2016 \quad$ Accepted: December 29, $2016 \quad$ Published: January 31, 2017

Copyright: Liu et al. This is an open-access article distributed under the terms of the Creative Commons Attribution License 3.0 (CC BY 3.0), which permits unrestricted use, distribution, and reproduction in any medium, provided the original author and source are credited.

\section{ABSTRACT}

Cancer progression depends on tumor growth and metastasis, which are activated or suppressed by multiple genes. An individual microRNA may target multiple genes, suggesting that a miRNA may suppress tumor growth and metastasis via simultaneously targeting different genes. However, thus far, this issue has not been explored. In the present study, the findings showed that miR-1 could simultaneously inhibit tumor growth and metastasis of gastric and breast cancers by targeting multiple genes. The results indicated that miR-1 was significantly downregulated in cancer tissues compared with normal tissues. The miR-1 overexpression led to cell cycle arrest in the $\mathbf{G 1}$ phase in gastric and breast cancer cells but not in normal cells. Furthermore, the miR-1 overexpression significantly inhibited the metastasis of gastric and breast cancer cells. An analysis of the underlying mechanism revealed that the simultaneous inhibition of tumor growth and metastasis mediated by miR-1 was due to the synchronous targeting of 6 miR-1 target genes encoding cyclin dependent kinase 4, twinfilin actin binding protein 1, calponin 3, coronin 1C, WAS protein family member 2 and thymosin beta 4, X-linked. In vivo assays demonstrated that miR-1 efficiently inhibited tumor growth and metastasis of gastric and breast cancers in nude mice. Therefore, our study contributed novel insights into the miR-1's roles in tumorigenesis of gastric and breast cancers.

\section{INTRODUCTION}

Cancer is the most common cause of disease-related death in humans worldwide, with more than 10 million new cases every year [1]. Tumor development and progression is a multistep process, in which cells progress from benign to malignant tumors. Currently, six hallmarks of cancers have been proposed to constitute an organizing principle that provides a solid foundation for the understanding of cancer biology [2]. The six hallmarks of cancers can enable tumor growth and metastatic dissemination. Therefore, the inhibition of tumor growth and metastatic dissemination is the primary challenge of cancer therapy. Standard cancer treatments currently include surgical intervention, radiation and chemotherapeutic drugs. However, radiation and chemotherapeutic drugs can kill normal cells and cause toxicity in patients. In recent years, many chemotherapeutic drugs targeting cancer-related molecules have been discovered and tested in clinical trials due to an improved understanding of tumor biology. ZSKT474, a PI3K inhibitor, suppresses tumor growth by inducing G0/G1 arrest and is in a phase I clinical trial for the treatment of solid tumors [3]. Epidermal growth factor receptor (EGFR)-targeted monoclonal antibodies (mAbs), such as panitumumab and cetuximab, have had an impact on metastatic colorectal cancer therapy [4]. The RAS proteins, key regulators of malignant transformation, are aberrantly expressed in most human tumors. Rational 
therapies that target the RAS pathways may inhibit tumor growth, survival and metastasis [5, 6]. Tumor development and metastasis depend on the regulation of gene expression. As novel cancer therapeutic agents, microRNAs (miRNAs) have attracted an increasing amount of attention for their capacity to activate or suppress tumor-associated gene expression.

miRNAs are a group of small noncoding RNAs that suppress gene expression by base pairing with $3^{\prime}$-untranslated region $\left(3^{\prime}\right.$-UTR) of the target mRNAs, resulting in mRNA degradation or translation inhibition [7]. Thus far, many reports have identified miRNAs roles in various cellular processes, including differentiation, apoptosis, cell proliferation, metabolism, immunity, and development. Abnormal miRNAs expression is associated with different pathological conditions, such as cardiovascular and neuronal disorders, inflammation, and cancer [8]. Experimental and clinical studies have demonstrated that aberrations in miRNAs expression are associated with tumorigenesis and cancer metastasis. miR-148b, which is frequently down-regulated in gastric cancer, can suppress gastric cancer cell growth by targeting the cholecystokinin-B receptor [9]. miR-200 is shown to inhibit cancer cell migration by directly targeting the transcription factors ZEB1 and ZEB2 [10]. The forced expression of miR-200 abrogates the capacity of tumor cells to invade and metastasize from primary tumors [11]. In most human malignancies, miR-21 acts as an oncogene by silencing the expression of many tumor suppressor genes related to proliferation, apoptosis and invasion [12]. However, the majority of studies on miRNAs have focused on one miRNA and one target gene. In fact, miRNAs exhibit enormous regulatory potential, because a single miRNA is generally believed to target multiple mRNAs $[13,14]$. For example, miRNAs from the miR-16 family induce $\mathrm{G} 0 / \mathrm{G} 1$ cell cycle arrest by silencing multiple cell cycle genes simultaneously, including Cyclin D1, Cyclin D3, Cyclin E1 and $C D K 6$, rather than an individual target [15]. However, no reports have examined whether an individual miRNA can simultaneously function in tumorigenesis and cancer metastasis by regulating different target genes. Therefore, we aimed to identify a multifunctional miRNA that can suppress both tumor growth and metastasis by synchronously targeting multiple genes.

To address this issue, miR-1 was characterized in this study. The results indicated that miR-1 was differentially expressed in both cancerous and normal cells. Further analysis showed that miR-1 simultaneously targeted CDK4 (cyclin-dependent kinase 4), TWF1 (twinfilin actin binding protein 1), WASF2 (WAS protein family, member 2), CNN3 (calponin 3, acidic), CORO1C (coronin, actin binding protein, 1C) and TMSB $4 X$ (thymosin beta 4, X-linked), key genes involved in the cell cycle and metastasis, leading to the simultaneous inhibition of tumor growth and metastasis.

\section{RESULTS}

\section{Downregulation of miR-1 in cancer cells and gastric cancer tissues}

To reveal the role of miR-1 in tumorigenesis, the expression levels of miR-1 in the cells of skin cancer, breast cancer and gastric cancer, three of the most common malignant cancers worldwide, were examined. The quantitative real-time PCR results showed that the miR-1 expression was significantly decreased in all cancer cells compared with that in the corresponding normal cells (Figure 1A), indicating that miR-1 might be a tumor suppressor. The cancer cell metastasis analysis revealed that the miR-1 overexpression in human skin cancer A375 cells had no effect the cancer cell migration compared with the control (Figure 1B). Thus human skin cancer A375 cells were not included in the following assays.

To further characterize the differential expression of miR-1 in gastric cancerous and normal cells, the primary tumor specimens from 10 patients with gastric cancer were assayed. The results showed that the miR-1 expression level in cancerous tissues was significantly lower than that in the paired normal tissues (Figure 1C). To evaluate the miR-1 expression in more clinical samples, 42 pairs of cancerous tissues and corresponding normal tissues from the same patients with gastric cancer were examined. The results indicated that there was a significant correlation between miR-1 expression level and tumorigenesis (Figure 1D).

Based on the degree of tumor cell differentiation detected histopathologically, the gastric primary tumors were classified into three grades, i.e., grade 1,2 or 3 . The data presented that the expression level of miR-1 was not correlated with tumor cell differentiation (Figure 1E), indicating that the miR-1 expression was downregulated in gastric cancers at various stages of differentiation.

Taken together, these findings revealed a significant correlation between miR-1 downregulation and primary human tumorigenesis.

\section{Inhibition of gastric and breast cancer cell growth by miR-1}

To investigate the role of miR-1 in cancer cell growth, miR-1 was overexpressed in gastric cancer cells (MGC-803, HGC-27 and MKN45) and normal gastric cells (GES-1) (Figure 2A). The results showed that the overexpression of miR-1 significantly inhibited the proliferation rates of gastric cancer cells compared with the negative control, while miR-1 overexpression had no effect on the growth of normal cells (Figure 2B). This inhibition of cancer cell proliferations by miR-1 suggested the involvement of miR1 in the cell cycle or/and cancer cell senescence.

To elucidate the mechanism underlying the miR-1mediated inhibition of gastric cancer cell growth, the cell cycle was analyzed in cells transfected with the precursor miR-1 and the negative control miRNA. The FACS analysis 
A
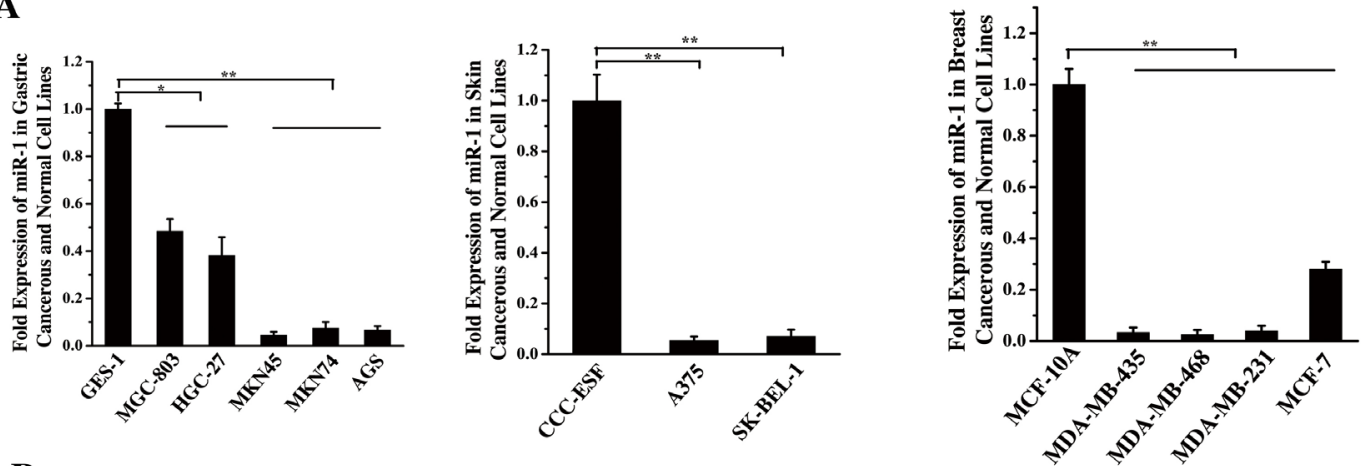

B
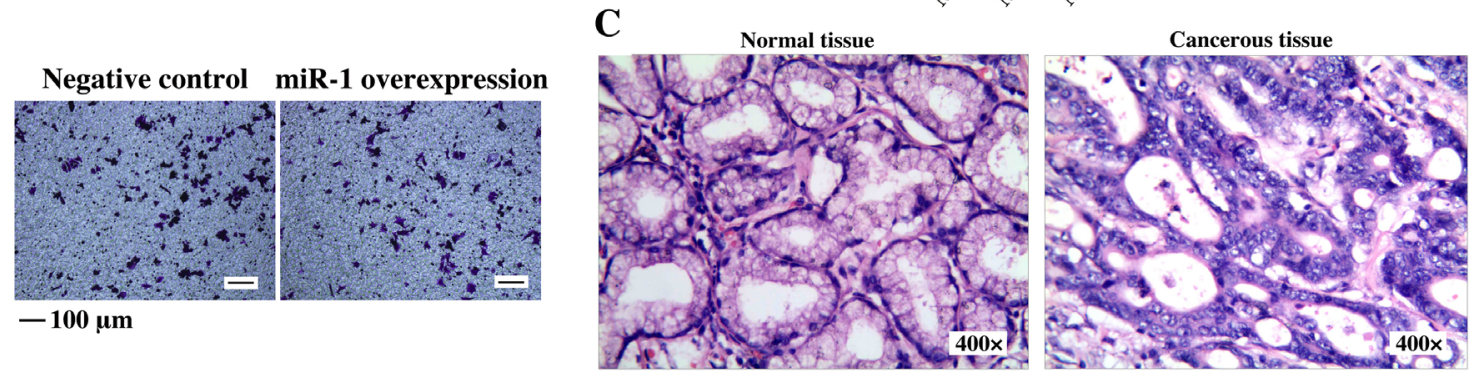

D
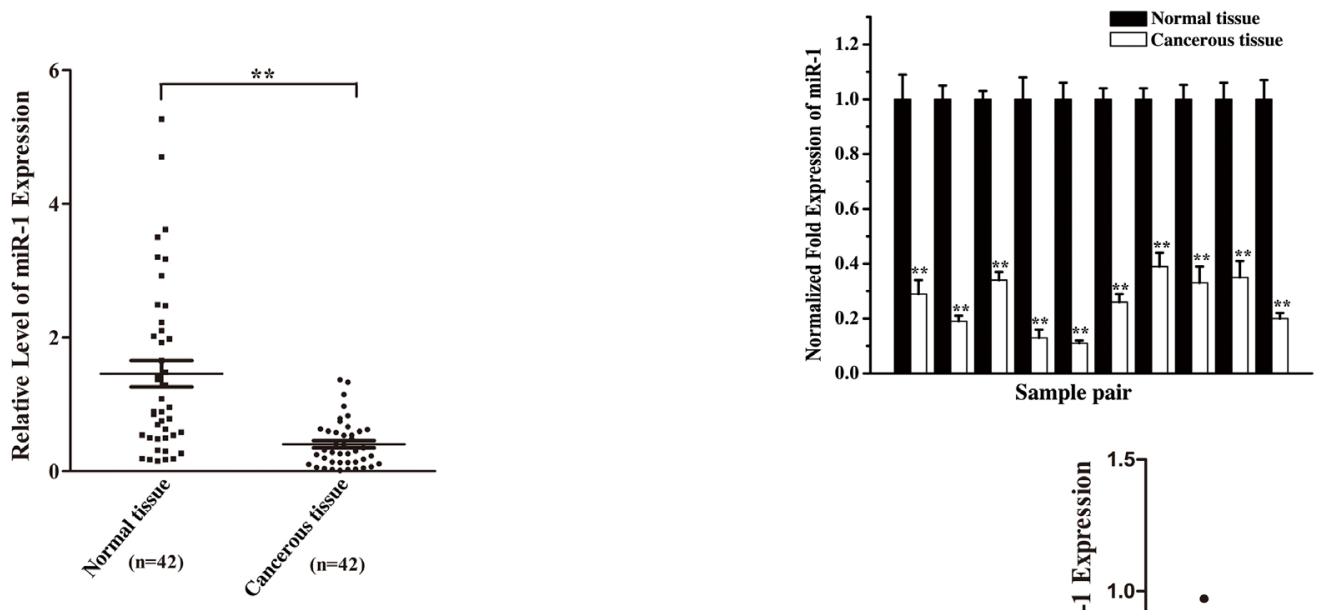

$\mathbf{E}$

Grade 1 (low malignancy)

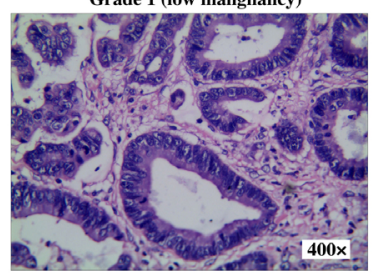

Grade 2 (medium malignancy)

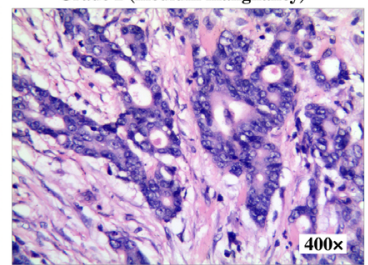

Grade 3 (high malignancy)

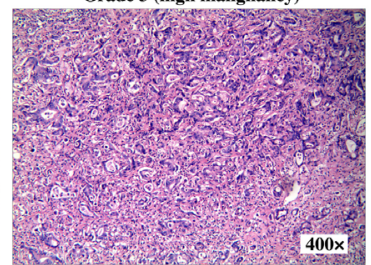

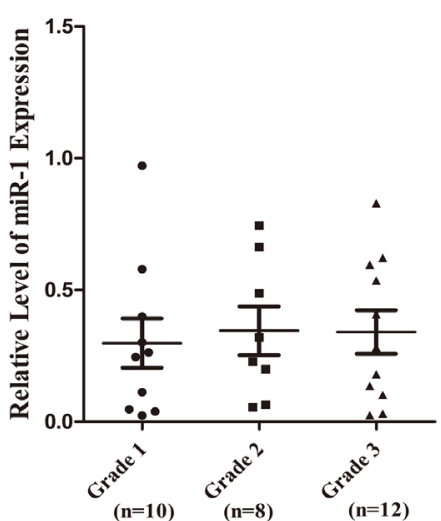

Figure 1: Downregulation of miR-1 in gastric cancer cells and tissues. A. The expression of miR-1 in gastric cancer, skin cancer, breast cancer and normal cell lines. miR-1 expression was measured by quantitative real-time PCR in cancer cells and compared with that in the normal GES-1, CCC-ESF and MCF-10A cells. B. Influence of miR-1 overexpression on human skin cancer A375 cell migration. A375 cells were transfected with the miR-1 precursor or the negative control. At $48 \mathrm{~h}$ after transfection, cell migration was examined. Representative images are shown. Scale bar, $100 \mu \mathrm{m}$. C. The expression of miR-1 in tumor specimens from gastric cancer patients. Cancerous tissue and corresponding normal tissue from the same patients were examined as paired samples $(\mathrm{n}=10)$. The samples were characterized using haematoxylin and eosin staining $(400 \times)$ and quantitative real-time PCR of miR-1. D. Scatter plot showing the expression level of miR-1 in tumor $(n=44)$ and corresponding normal samples $(n=42)$ from gastric cancer patients. The expression of miR-1 was measured using quantitative real-time PCR. E. The expression of miR-1 in gastric cancers at various stages of differentiation. Cancer tissue samples were divided into three grades using hematoxylin and eosin staining $(400 \times)$. The expression level of miR-1 in grade $1(\mathrm{n}=10)$, grade $2(\mathrm{n}=8)$ and grade $3(\mathrm{n}=12)$ samples was analyzed by quantitative real-time PCR. Statistically significant differences are indicated with asterisks $(*, p<0.05 ; * * p<0.01)$. 
A

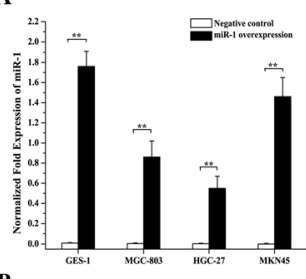

B
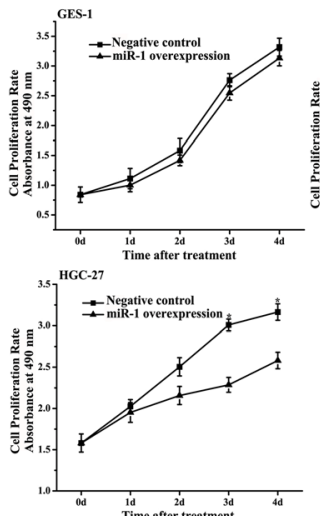

C
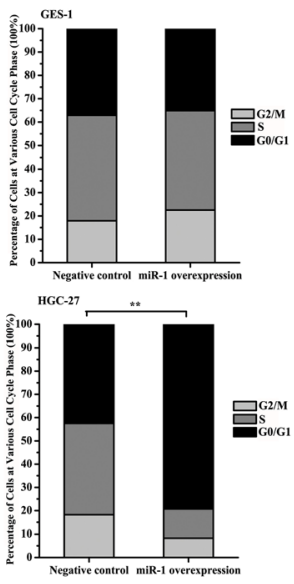
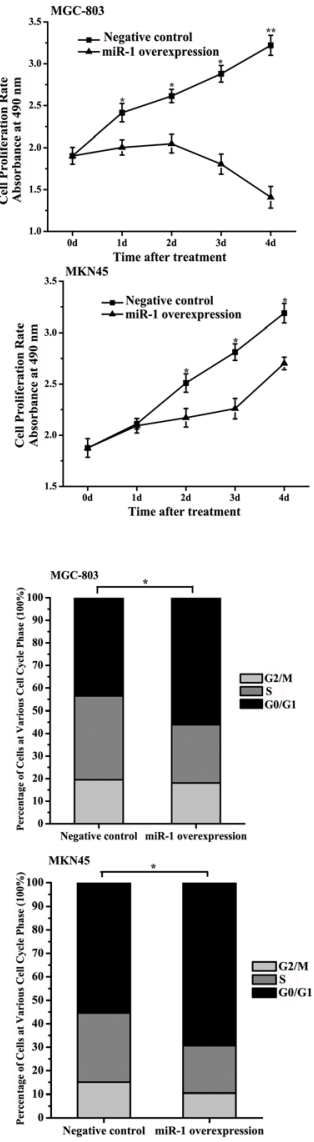

D

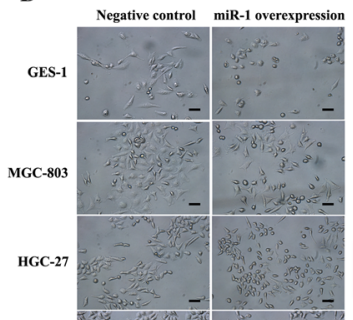

E

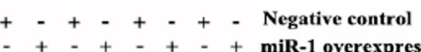
GES-1 MCC-803 HGe +-+ miR-1 overexpression HGC-27 MKN45 $---\infty-\cdots$ pRb (phospho S811) - $\beta$-actin

F
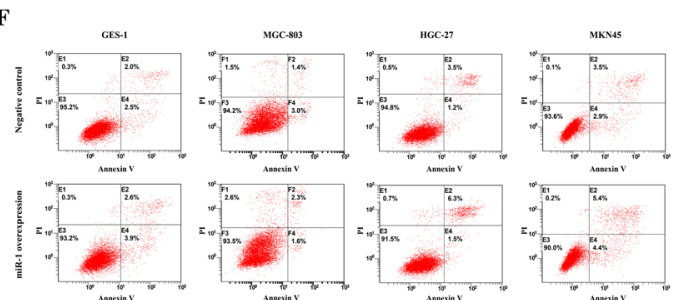

G

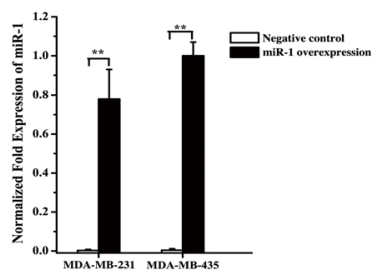

H
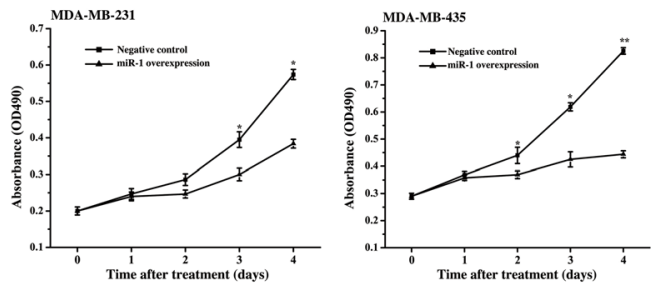

I
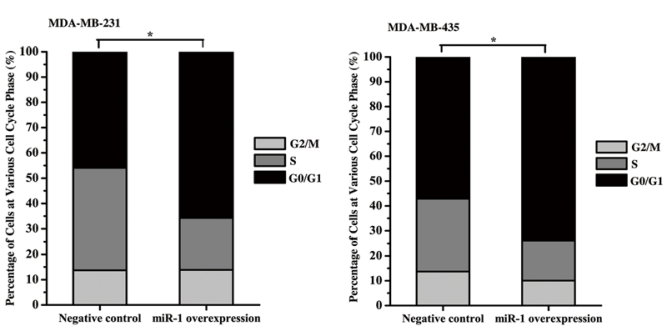

Figure 2: Effects of miR-1 on the growth of gastric and breast cancer cells and normal cells. A. miR-1 overexpression in gastric cancer and normal cells. MGC-803, HGC-27, MKN45 and GES-1 cells were transfected with the miR-1 precursor or the negative control miRNA. At $48 \mathrm{~h}$ after transfection, the miR-1 expression was detected with quantitative real-time PCR. B. Cell proliferation rate. Cells were transfected with the precursor miR-1 or the negative control miRNA. From $1 \mathrm{~d}$ to $5 \mathrm{~d}$ after transfection, cell growth was examined using cell proliferation assays. C. Effects of miR-1 on the cell cycle. At $48 \mathrm{~h}$ after cells were transfected with the miR-1 precursor or the negative control, the cell cycle of cancer and normal cells was evaluated with flow cytometry. D. Cell senescence analysis. Cells transfected with the precursor miR-1 or the negative control miRNA were treated using senescence-associated $\beta$-galactosidase staining. Representative images are shown. Scale bar, $100 \mu \mathrm{m}$. E. Detection of pRb phosphorylation. Cells treated with the precursor miR-1 or the negative control miRNA were subjected to Western blot analysis with the phosphorylated pRb antibody (P-pRb). $\beta$-Actin was used as a control. F. Detection of gastric cancer cell apoptosis using flow cytometry. Cells transfected with the precursor miR-1 or the negative control miRNA were subjected to apoptosis assays with AnnexinV. G. The overexpression of miR-1 in breast cancer cells. Breast cancer cells (MDA-MB-231 and MDA-MB-435) were transfected with $30 \mathrm{nM}$ of the miR-1 precursor or the negative control miRNA. After $48 \mathrm{~h}$ after, the cells were analyzed using quantitative real-time RT-PCR. H. The effect of miR-1 overexpression on breast cancer cell proliferation. Breast cancer cells were transfected with $30 \mathrm{nM}$ of the miR-1 precursor or the negative control miRNA. Then, cell growth was examined daily. I. Effects of miR-1 overexpression on breast cancer cell cycle. The breast cancer cells transfected with the miR-1 precursor were subjected to cell cycle assays. In all panels, data are shown as mean \pm standard deviation from three independent experiments $(* p<0.05 ; * *<0.01)$. 
showed that the numbers of cells at G0/G1 phase in the miR1-overexpressing HGC-27, MGC-803 and MKN45 cells were significantly increased compared with the controls (Figure 2C). However, miR-1 overexpression had no effect on the cell cycle of GES-1 cells (Figure 2C). These data indicated that miR-1 could initiate cell cycle arrest in the G0/ G1 phase in cancer cells but not normal cells, contributing to the inhibition of cancer cell proliferation by miR-1.

To evaluate the effects of miR-1 on cell senescence, MGC-803, HGC-27, MKN45 and GES-1 cells were transfected with the miR-1 precursor, and were then examined for senescence. The senescence-associated $\beta$-galactosidase staining results revealed that not all cells were stained, indicating that senescence did not occur in the miR-1-overexpressing cancer and normal cells (Figure 2D). Moreover, the analysis of the $\mathrm{pRb}$ the phosphorylation, in which decreased phosphorylation is a marker of cell senescence [11], revealed that $\mathrm{pRb}$ was phosphorylated in all cells (Figure 2E), indicating that miR-1 did not affect gastric cancer cell senescence. The apoptosis assays demonstrated that percentages of apoptotic miR-1-overexpressing cancer cells were similar to those of the controls (Figure 2F), indicating that miR-1 had no effect on the apoptosis of gastric cancer cells.

The above data revealed that the miR-1-mediated inhibition of gastric cancer cell proliferation but not normal cell proliferation was due to cancer cell cycle arrest in G0/G1 phase.

To evaluate the role of miR-1 in the regulation of the cell cycle of breast cancer cells, miR-1 was overexpressed in MDA-MB-231 and MDA-MB-435 breast cancer cells (Figure $2 \mathrm{G}$ ). The cell proliferation assay results indicated that miR-1 overexpression inhibited breast cancer cell growth compared with the control (Figure $2 \mathrm{H}$ ). In addition, the cell cycle analysis showed that the number of cells in the G0/G1 phase was $20 \%$ higher after transfection with the miR-1 precursor than with the negative control (Figure 2I), indicating that miR-1 had a positive effect on breast cancer cell cycle arrest in the G0/G1 phase. These results indicated that miR-1 triggered the cycle arrest in G1/G0 phase, resulting in the inhibition of breast cancer cell growth.

Taken together, these findings revealed that miR-1 could function as a gastric and breast cancer suppressor by inducing cell cycle arrest.

\section{Mechanism of miR-1-mediated inhibition of gastric and breast cancer cell growth}

To explore the molecular mechanism of miR-1mediated cell cycle arrest in cancer cells, the miR-1 targets related to the cell cycle were predicted using the miRanda, TargetScan and PicTar algorithms. The results showed that 41 genes including $C D K 4$ were the potential targets of miR-1 (Figure 3A). To further reveal the genes targeted by miR-1, miR-1 was overexpressed in cells, and the expression levels of the 41 target genes were then detected. The quantitative real-time PCR data revealed that
$C D K 4$ was significantly downregulated compared with the controls when miR-1 was overexpressed (Figure 3B). However, the expression levels of the other 40 potential targets related to the cell cycle showed little change in response to miR-1 overexpression (data not shown). The results indicated that $C D K 4$, a key gene required for the G1-S transition in the cell cycle [12], was a target of miR1. This gene contains an miR-1 recognition site in the 3'UTR of CDK4 (Figure 3A). To determine whether miR1 could directly interact with $C D K 4$, the $C D K 43^{\prime} \mathrm{UTR}$ and $C D K 4$ 3'UTR mutant constructs were generated (Figure 3A). Then, cells were co-transfected with the constructs and miR-1. The dual-luciferase reporter assays indicated that the luciferase activity after the treatment with miR-1+ CDK4 3'UTR was significantly reduced compared with that of the controls (Figure 3C), indicating that miR-1 bound to the 3'UTR of CDK4. The above data revealed that $C D K 4$ was a target gene of miR-1.

To assess the effect of miR-1 overexpression on the expression of CDK4 in vivo, the miR-1 precursor was transfected into the gastric or breast cancer cells, and then the CDK4 protein level was determined. The Western blot results indicated that miR-1 overexpression led to a significant decrease in the level of CDK4 protein in the examined cells (Figure 3D and 3E), indicating that miR-1 could target $C D K 4$ in gastric or breast cancer cells.

These results demonstrated that miR-1 could mediate gastric or breast cancer cell cycle arrest in the G0/ G1 phase by directly targeting the $C D K 4$ gene (Figure $3 \mathrm{~F}$ ).

\section{Effects of miR-1 on gastric and breast cancerous cell metastasis}

To evaluate the effect of miR-1 on the metastasis of gastric cancer cells, miR-1 was overexpressed in cancer cells, followed by detection of cancer cell migration, adhesion and invasion. The results revealed that the miR1 overexpression significantly inhibited the migration of gastric cancer cells (MGC-803, HGC-27 and MKN45) but not that of normal cells (GES-1) (Figure 4A), indicating that miR-1 might be required for gastric cancer cell metastasis.

The data from the cell adhesion assays showed that the number of adherent cancer cells (MGC-803, HGC-27 or MKN45) was significantly decreased compared with the control when miR-1 was overexpressed in cancer cells (Figure 4B). However, miR-1 overexpression had no significant effect on the number of adherent normal cells (GES-1) (Figure 4B). These results indicated that miR-1 could inhibit the adhesion of gastric cancer cells. At the same time, the cell invasion assays showed that miR-1 overexpression led to a significant decrease in the invasion of cancer cells (MGC-803, HGC-27 or MKN45), whereas the invasion of normal cells (GES-1) was not affected by miR-1 (Figure 4C). The data revealed that miR-1 could inhibit the metastasis of gastric cancer cells.

The cell migration and invasion assay results indicated that the miR-1 overexpression significantly 
inhibited the breast cancer cell migration and invasion (Figure 4D and 4E). At the same time, the MDAMB-231 and MDA-MB-435 breast cancer cells displayed significant decreases in their attachments to fibronectin (Figure 4F). These data showed that miR-1 could inhibit the metastasis of breast cancer cells.

\section{MiR-1-mediated pathway for cancer cell metastasis}

The target genes of miR-1 were predicted to elucidate the role of miR-1 in cancer cell metastasis. The results indicated that 35 genes associated with cell migration might be targeted by miR-1 (Figure 5A).

A

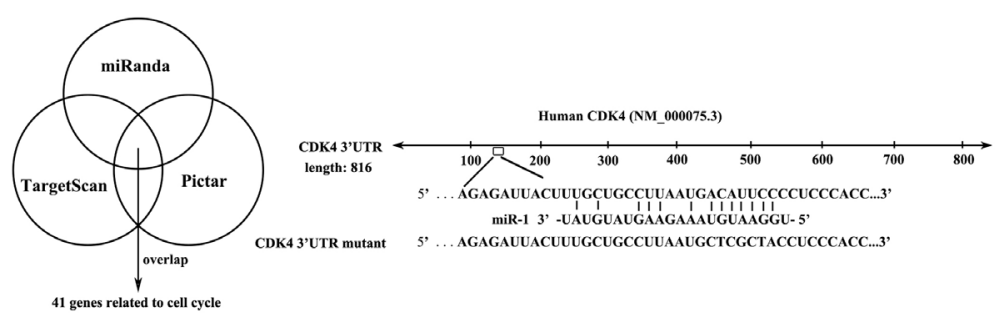

B

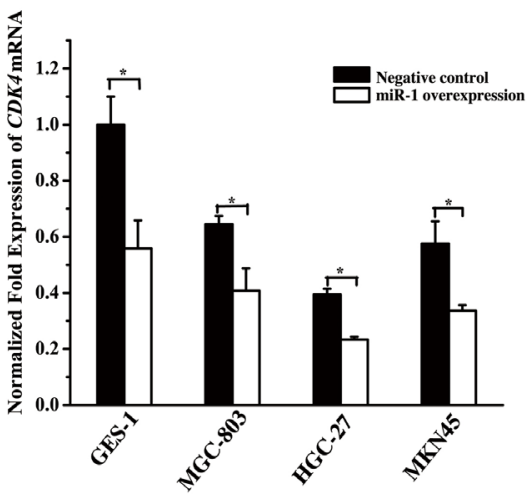

C

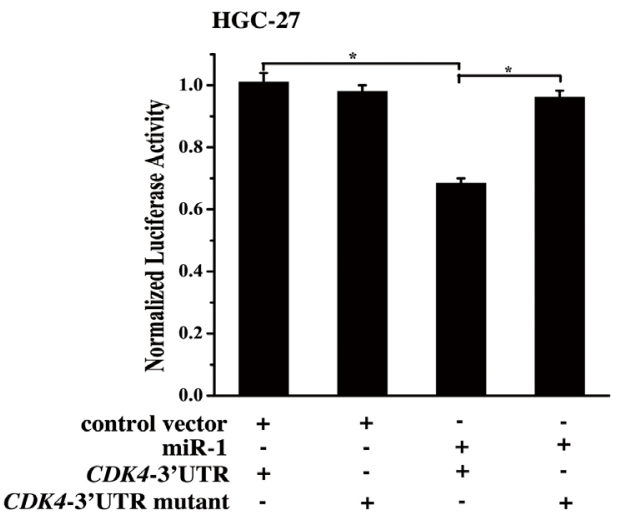

D

$+-++\quad+-\quad+\quad-$ Negative control $-+-+\quad+\quad+\quad+$ miR-1 overexpression GES-1 MGC-803 HGC-27 MKN45

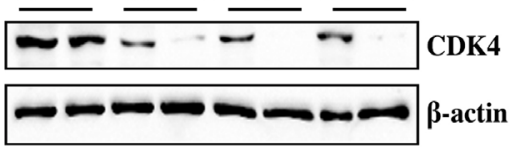

$\mathbf{E}$ $\begin{array}{ccccc}+ & - & + & - & \text { Negative control } \\ - & + & - & + & \text { miR-1 overexpression } \\ \text { MDA-MB-231 } & \text { MDA-MB-435 }\end{array}$

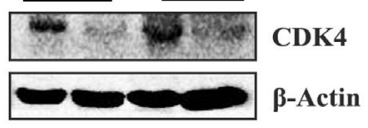

$\mathbf{F}$

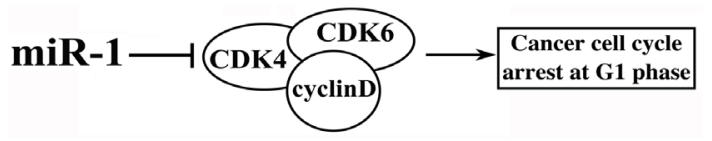

Figure 3: Mechanism of gastric and breast cancer cell cycle regulation mediated by miR-1. A. Prediction of miR-1 target genes. The miR-1 targets related to the cell cycle were predicted using the miRanda, TargetScan and PicTar algorithms. CDK4 was predicted to be a target gene of miR-1. B. Expression levels of endogenous $C D K 4$ in response to miR-1 overexpression in cells. Cells were transfected with the miR-1 precursor or the negative control. Twenty hours later, the level of CDK4 mRNA was detected using quantitative real-time PCR. C. Interaction between miR-1 and CDK4. The miR-1 construct or the vector only and the luciferase plasmid containing the 3'UTR of CDK4 mRNA or its mutant were co-transfected into HGC-27 cells. Then the luciferase activities were detected. The Renilla luciferase values were normalized to the firefly luciferase values. D. Western blot analysis of CDK4. Cells were treated with $30 \mathrm{nM}$ of the miR-1 precursor or the negative control RNA for $48 \mathrm{~h}$ and whole-cell extracts were analyzed by Western blot analysis. $\beta$-actin was used for protein loading correction. E. Effects of miR-1 overexpression on its target gene expression in breast cancer cells. Breast cancer cells were transfected with $30 \mathrm{nM}$ of the miR-1 precursor or the negative control miRNA. After $48 \mathrm{~h}$, the expression of CDK4 in the cells was analyzed by Western blot. $\beta$-actin was used as a control. F. Model for the miR-1-mediated pathway in the cell cycle of cancer cells. Statistically significant differences are indicated with asterisks $(*, p<0.05 ; * * p<0.01)$. 
$\mathbf{A}$
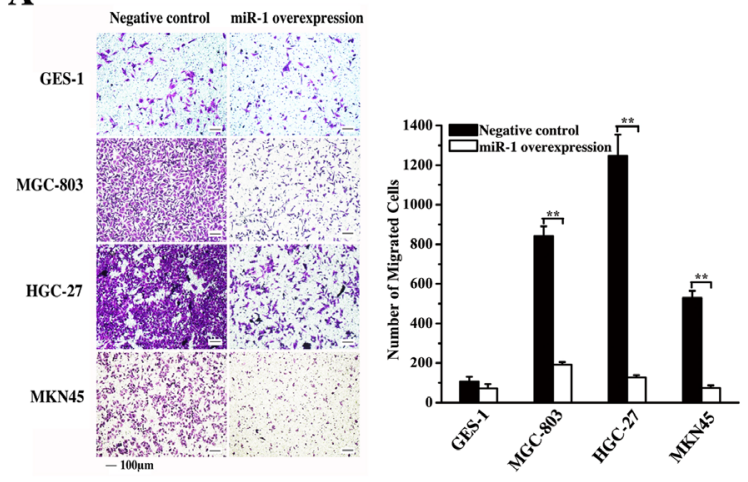

$\mathbf{C}$

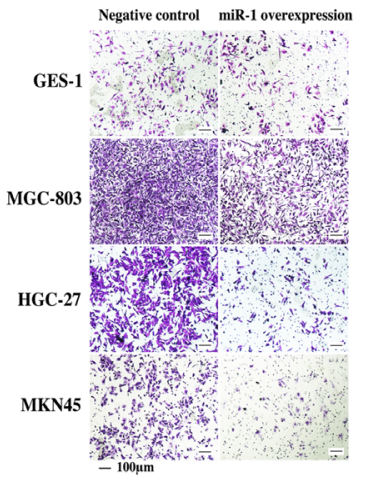

D
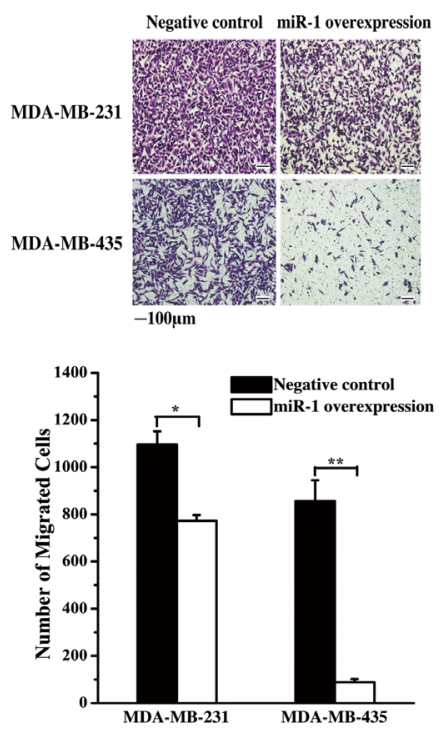

B

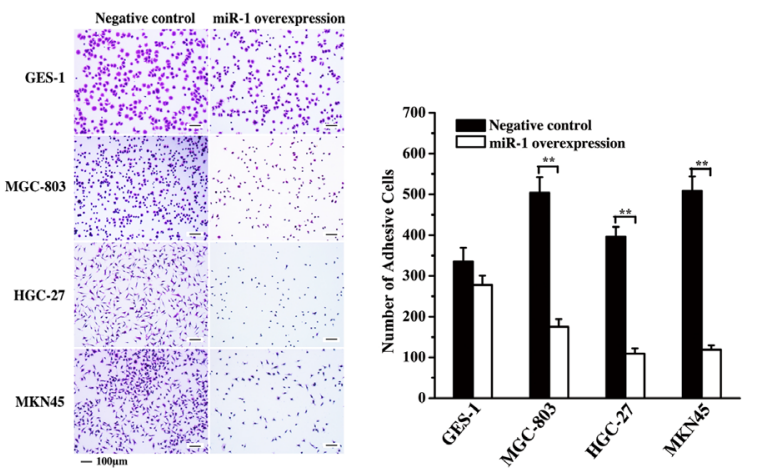

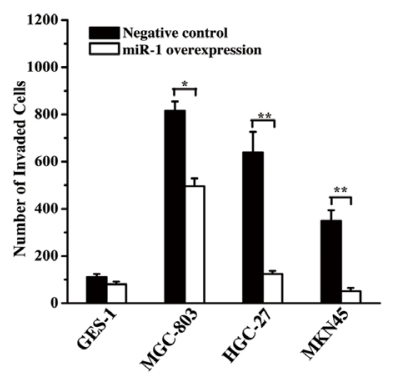

E
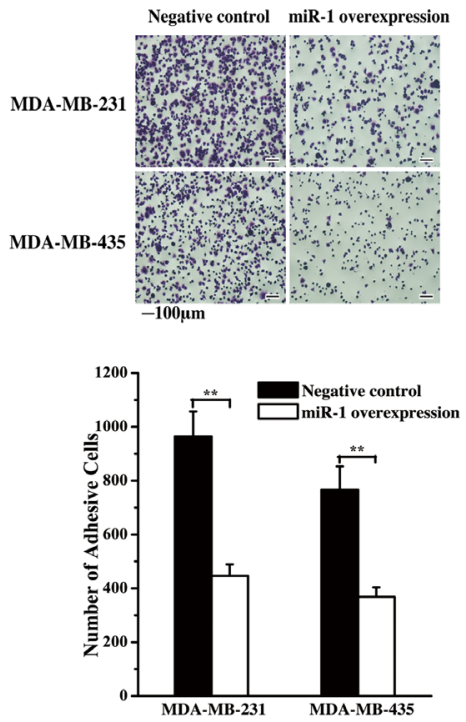

F
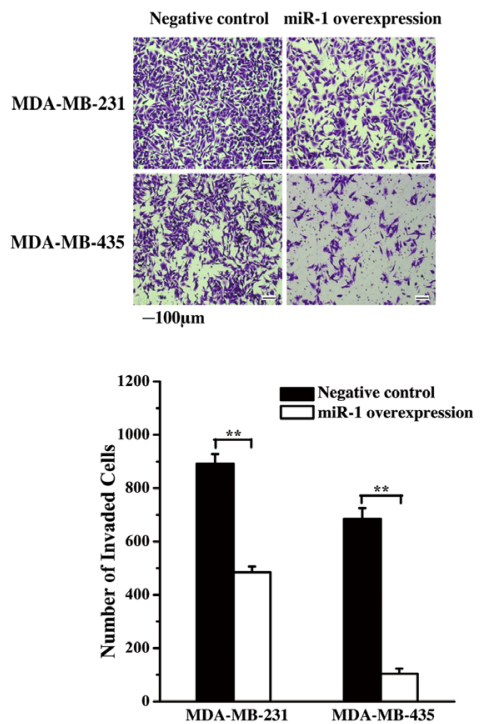

Figure 4: Effects of miR-1 on gastric and breast cancerous cell metastasis. A. Effect of miR-1 on gastric cancer cell metastasis. Gastric cancer cells (MGC-803, HGC-27 and MKN45) and the normal cells (GES-1) were transfected with the miR-1 precursor or the negative control. At $48 \mathrm{~h}$ after transfection, cell migration was examined, and the data were analyzed. Representative images are shown. Scale bar, $100 \mu \mathrm{m}$. B. Effects of miR-1 overexpression on the adhesion of gastric cancer cells. The cells were transfected with the miR1 precursor or the negative control and then cultured for $48 \mathrm{~h}$. The number of adherent cells was evaluated. Representative images are shown. Scale bar, $100 \mu \mathrm{m}$. C. The role of miR-1 in cancer cell invasion. miR-1 precursor-transfected cells were cultured for $48 \mathrm{~h}$. Then, the cells were characterized with cell invasion assays. Scale bar, $100 \mu \mathrm{m}$. D. Evaluations of breast cancer cell migration. MDA-MB-231 and MDA-MB- 435 cells were transfected with $30 \mathrm{nM}$ of the miR-1 precursor or the negative control miRNA to overexpress miR-1. At 48 $\mathrm{h}$ after transfection, the migrated cells were examined. Representative images are shown. Scale bar, $100 \mu \mathrm{m}$. E. The influence of miR-1 overexpression on breast cancer cell invasion. At $48 \mathrm{~h}$ after miR-1 overexpression, the invaded cells were evaluated. Representative images are provided. Scale bar, $100 \mu \mathrm{m}$. F. Cell adhesion assays. Breast cancer cells treated with the miR-1 precursor were cultured for $48 \mathrm{~h}$, then, the adherent cells were examined. Representative images are indicated. Scale bar, $100 \mu \mathrm{m}$. In all panels, asterisks represent statistically significant differences between treatments $\left({ }^{*}, p<0.1 ;{ }^{* *}, p<0.05\right)$. 
A

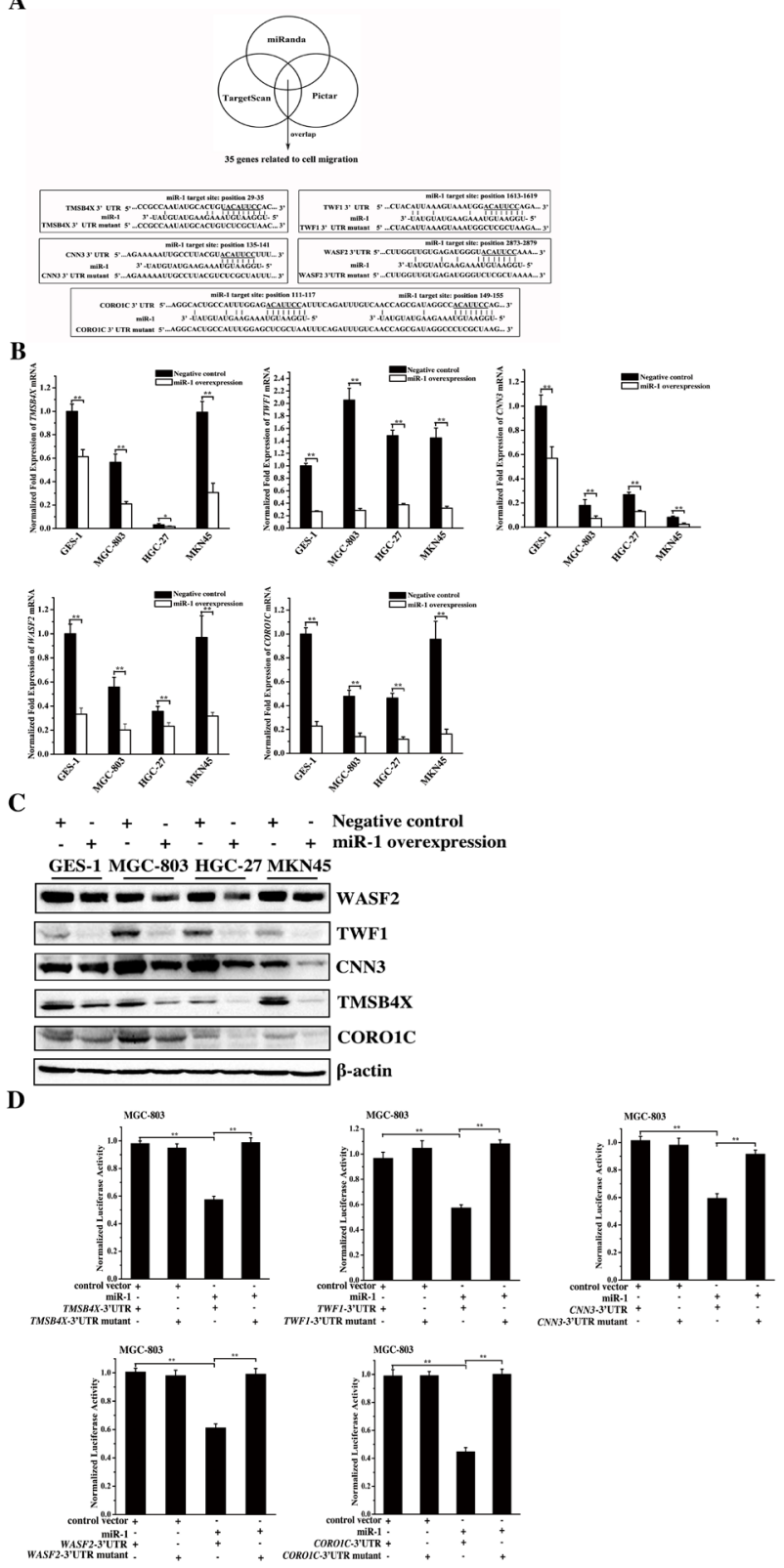

$\mathbf{E}$

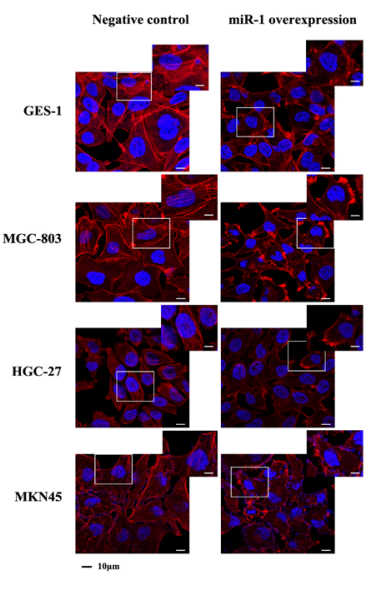

F

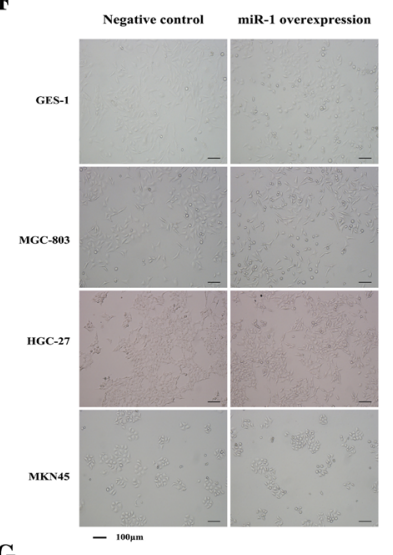

G

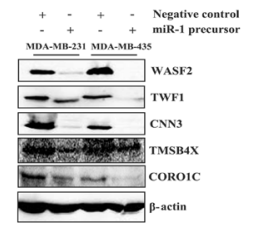

$\mathbf{H}$

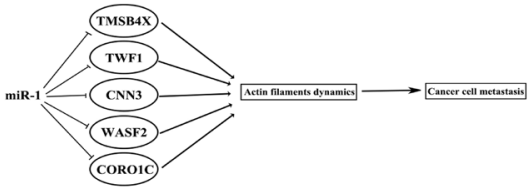

Figure 5: The miR-1-mediated pathway for cancer cell metastasis. A. The prediction of genes targeted by miR-1. As predicted, 35 genes associated with cell migration were miR-1 targets. The genes (TMSB 4X, TWF1, CNN3, WASF2 and CORO1C) targeted by miR-1 are indicated in the boxes. B. The interactions between miR-1 and its targets in vivo. The miR-1 precursor or the negative control miRNA was transfected into gastric cancer cells (MGC-803, HGC-27 and MKN45) and the normal cells (GES-1). At $24 \mathrm{~h}$ after transfection, the mRNAs of the 35 target genes of miR-1 were detected using quantitative real-time PCR. Among the 35 target genes, 5 genes (TMSB $4 X$, $T W F 1, C N N 3, W A S F 2$ and CORO1C) were significantly downregulated in response to miR-1 overexpression. C. The influence of miR-1 on target gene expression. Cells were transfected with the miR-1 precursor or the negative control miRNA. At $24 \mathrm{~h}$ after transfection, the proteins encoded by the target genes were examined using Western blot analysis. The antibodies used are indicated at the right. D. The direct interactions between miR-1 and its target genes. The miR-1 precursor and the 3' UTR of TMSB 4X, TWF1, CNN3, WASF2 or CORO1C were co-transfected into MGC-803 cells. Luciferase activity was measured at $24 \mathrm{~h}$ after transfection. And the ratio of firefly luciferase activity to Renilla luciferase activity is shown. E. Effects of miR-1 on the actin filament formation. Cells treated with the miR-1 precursor or negative control miRNA for $48 \mathrm{~h}$ were stained with rhodamine-phalloidin (red) and DAPI (blue) to label F-actin and nuclei, respectively. Then stained cells were subjected to confocal microscopy. Scale bar, $10 \mu \mathrm{m}$. F. The influence of miR-1 on cell morphology. The morphology of miR-1-overexpressing cells was examined with optical microscopy. Scale bar, $100 \mu \mathrm{m}$. G. Western blot analysis of WASF2, TWF1, CNN3, TMSB4X and CORO1C. Breast cancer cells were treated with $30 \mathrm{nM}$ of the miR-1 precursor or the negative control miRNA and cultured for $48 \mathrm{~h}$. The whole-cell lysates were subjected to Western blot analysis. $\beta$-actin was used as a control. H. Model for the miR-1-mediated inhibitory mechanism of cancer cell metastasis. All experiments were biologically repeated three times. The data are shown as the mean \pm standard deviation $(* p<0.05, * * p<0.01)$. 
To confirm the target gene predictions, miR-1 was overexpressed in gastric cancer cells (MGC-803, HGC-27 and MKN45) and in the normal cells (GES-1). The miR1 overexpression significantly downregulated 5 genes (TMSB4X,TWF1, CNN3, WASF2 and CORO1C) of the 35 predicted target genes in the examined cells (Figure 5B). Western blot analysis yielded similar results (Figure 5C). These data indicated that TMSB $4 X, T W F 1, C N N 3$, $W A S F 2$ and CORO1C were the target genes of miR-1. To explore the direct interactions between miR-1 and the five target genes, the miR-1 precursor and the 3' UTR of TMSB4X,TWF1, CNN3, WASF2 or CORO1C were co-transfected into MGC-803 cells. The dual-luciferase reporter assay results indicated that miR-1 significantly reduced the activity of luciferase fused to the 3' UTR of TMSB 4X, TWF1, CNN3, WASF2 or CORO1C compared with the controls (Figure 5D), showing that these 5 genes could be directly targeted by $\mathrm{miR}-1$. These data presented that TMSB 4X, TWF 1, CNN3, WASF 2 and CORO1C genes were the targets if miR-1.

TMSB4X, CORO1C, CNN3, WASF2 and TWF1 are key components required for actin polymerization [13-17]. Therefore the effect of miR-1 on the fiber formation of actin was explored. The confocal microscopy data indicated that the formation of actin stress fibers was destroyed in miR-1-overexpressing cells compared with the control cells (Figure 5E). The miR-1 overexpression resulted in obvious morphological changes in the cells, including a decreased number of adherent cells and an increased number of round cells (Figure 5F).

To investigate the mechanism underlying the miR1 -mediated regulation of breast cancer cell metastasis, the expression levels of WASF2, TWF1, CNN3, TMSB $4 X$ and $C O R O 1 C$ genes in miR-1-overexpressing cells were examined. Western blot data indicated that miR1 overexpression significantly downregulated WASF2, TWF1, CNN3, TMSB4X and CORO1C (Figure 5G), showing that miR-1 could inhibit breast cancer cell metastasis by targeting the WASF2, TWF1, CNN3, TMSB $4 X$ and CORO1C genes.

Taken together, these data showed that miR-1 could inhibit cancer cell metastasis by targeting actin-associated genes, leading to the inhibition of actin cytoskeleton formation (Figure 5H).

\section{The underlying mechanism of miR-1-mediated synchronous suppression of tumor growth and metastasis}

The above data indicated that miR-1 could inhibit tumor growth and metastasis by targeting $C D K 4$ gene and TWF1, WASF2, TMSB $4 X, C N N 3$ and CORO1C genes, respectively. To explore whether miR-1 could simultaneously suppress tumor growth and metastasis by synchronously regulating the expressions of these six target genes, the miR-1-guided cleavage of the target
mRNAs in the Ago complex was investigated. The timecourse results showed that all six targets could be cleaved in the miR-1-Ago complex (Figure 6A). The miR-1guided cleavage of target mRNAs in the Ago complex occurred in a miRNA-concentration-dependent manner (Figure 6B), indicating that miR-1 could guide the cleavage of its targets. When the six target mRNAs were co-incubated at equivalent levels with the miR-1-Ago2 complex, all six mRNAs were cleaved (Figure 6C). These findings revealed that miR-1 could simultaneously guide the cleavage of its six target mRNAs.

To investigate whether miR-1 could synchronously target the mRNAs of its six target genes in cells, the colocalization of miR-1 and its targets was assessed. The confocal microscopy images showed that miR-1 was colocalized with the mRNAs of the six target genes (Figure $6 \mathrm{D})$. Therefore, miR-1 could simultaneously regulate the expressions of the six target genes in cells.

These findings presented that miR-1 simultaneously suppressed tumor growth and metastasis by synchronously targeting multiple genes.

\section{The miR-1-mediated suppression of tumor growth and metastasis in vivo}

To explore the role of miR-1 in tumorigenesis in vivo, miR-1 was overexpressed in gastric cancer cells (MGC-803) or breast cancer cells (MDA-MB-231), and the cancer cells were then injected into nude mice to examine the tumor growth. The results indicated that the tumor growth was significantly inhibited in the mice treated with miR-1-overexpressing MGC-803 cells or miR-1-overexpressing MDA-MB-231 cells compared with the control cells (Figure 7A). The tumor sizes of mice injected with miR-1-overexpressing MGC-803 or MDAMB-231 cells were significantly larger than those of the controls (Figure 7B). These data indicated that miR-1 could inhibit the growth of gastric and breast cancer tumor in vivo.

Quantitative real-time PCR analysis indicated that the expression level of miR-1 in tumors was 3.5-6 times higher than that in the controls (Figure 7C), showing the upregulation of miR-1 in gastric and breast cancers in vivo. The western blot data indicated that CDK4 protein was significantly downregulated in tumors derived from miR-1 overexpressing cancer cells compared with that in the controls (Figure 7D). These results showed that miR1 inhibited the growth of gastric and breast cancer by downregulating the expression of its target, CDK4, in vivo.

To investigate the influence of miR-1 on cancer metastasis in vivo, the animal model of breast cancer cell metastasis to lung was established according to the published protocols [6, 13, 19]. MDA-MB-231 cells expressing luciferase were transfected with the miR1 precursor, and these cells were then intravenously injected into mice via the tail vein. At the same time, the 
A
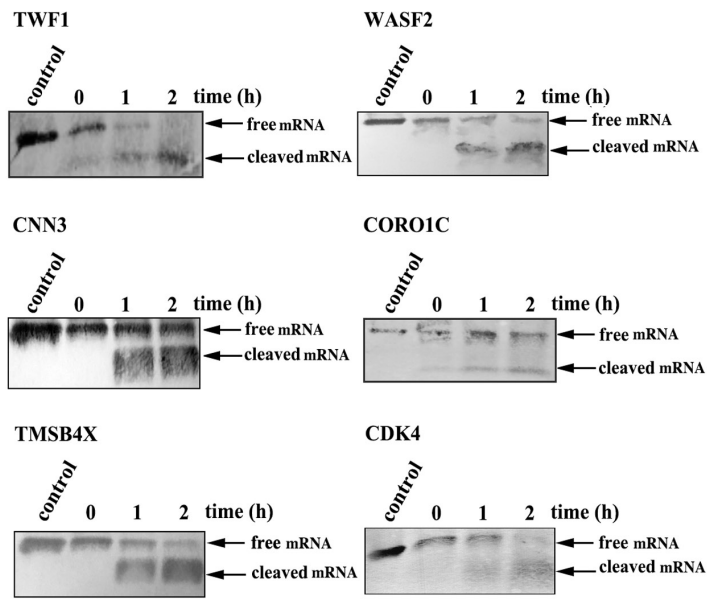

B

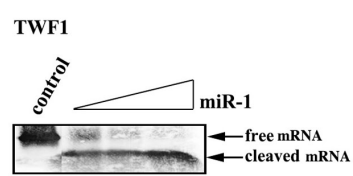

CNN3

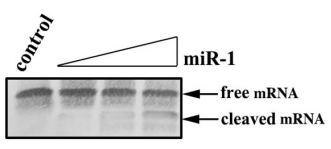

TMSB4X

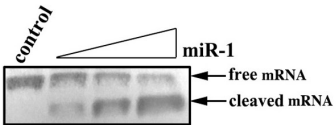

C

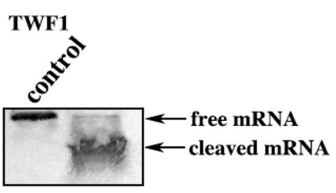

CNN3

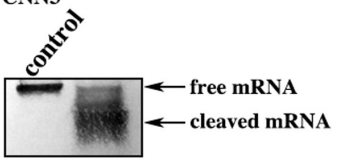

TMSB4X

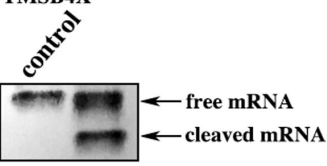

WASF2

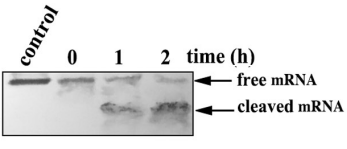

CORO1C

WASF2

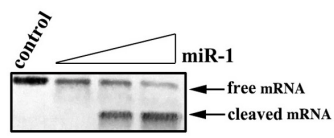

CORO1C

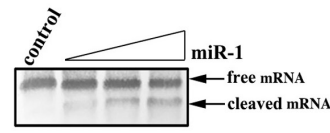

CDK4
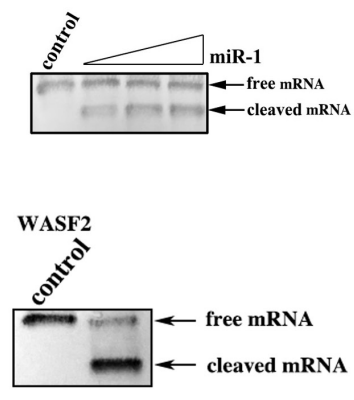

CORO1C

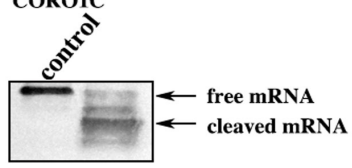

CDK4

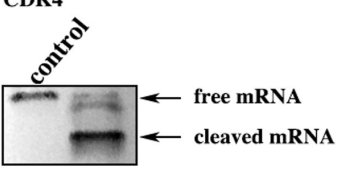

D

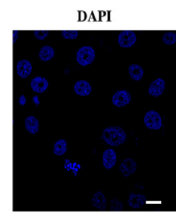

TWF1 mRNA

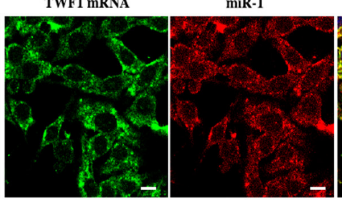

Merged
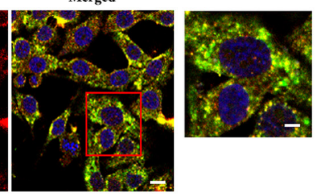

DAP

WASF2 mRNA

miR-1

Merged
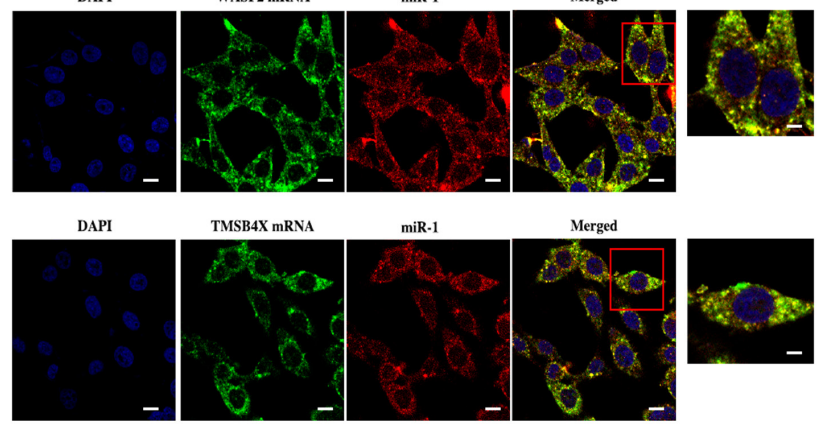

TMSB4X mRNA
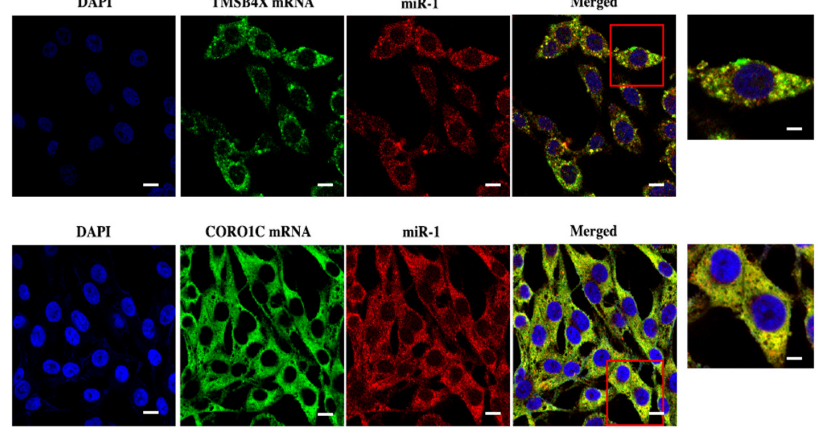

CORO1C mRNA

miR-1

Merged
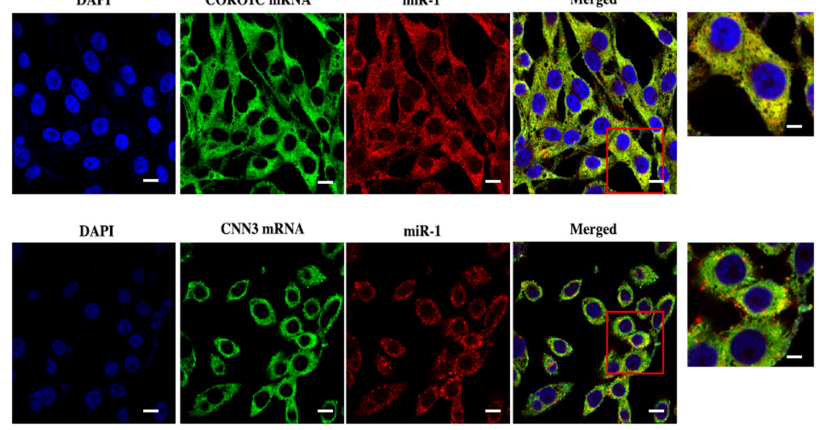

CNN3 mRNA
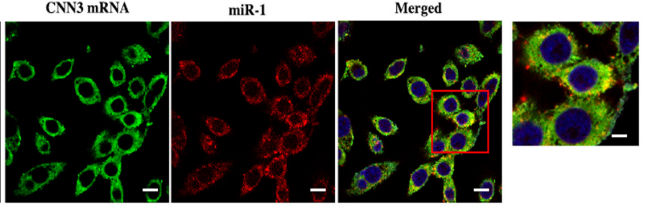

DAPI

CDK4 mRNA

miR-1

Merged

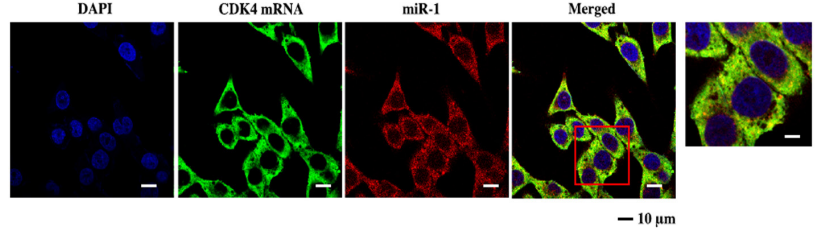

Figure 6: The simultaneous expression regulation of target genes by miR-1. A. The time-course assays of the miR-1-guided cleavage of target mRNAs. Each target mRNA of miR-1 was incubated with miR-1 and the Ago2 complex for various times at $37{ }^{\circ} \mathrm{C}$. The mRNA alone was used as a control. The cleavage products were examined using Northern blot analysis. The probes are shown at the top, and the numbers indicate the cleavage time. B. The effect of miR-1 concentration on target cleavage. Each miR-1 target mRNA was incubated with the Ago 2 complex and different concentrations of miR-1 for $1 \mathrm{~h}$. Then the cleavage products were detected by Northern blot analysis. The mRNA alone was used as a control. C. The miR-1-guided simultaneous cleavage of miR-1 target mRNAs. The mRNAs of all six miR-1 targets were equivalently co-incubated with the Ago2 complex and miR-1. One hour later, the cleavage products were examined by Northern blot analysis. The mRNA alone was used as a control. D. The intracellular co-localization of miR-1 and its six target genes. MDA-MB-435 cells were transfected with the miR-1 precursor and then cultured for $48 \mathrm{~h}$. The cells were subjected to fluorescence in situ hybridization using a DIG-labeled miR-1 probe and a biotin-labeled mRNA probe. Confocal microscopy images are presented. Green, target gene mRNA. Red, miR-1. Blue, nuclei. Scale bar, $10 \mu \mathrm{m}$. 
A

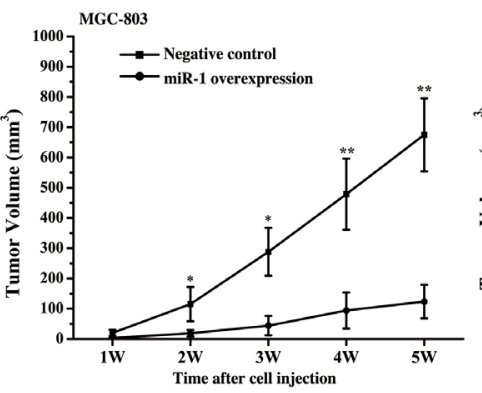

B

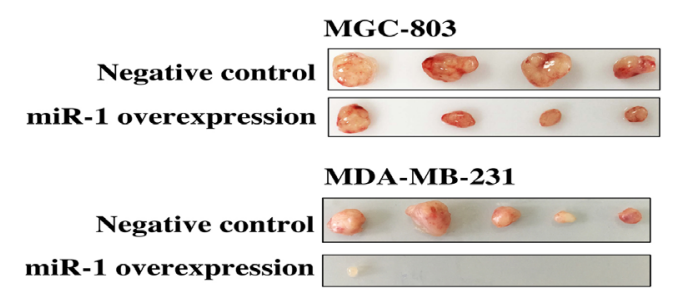

C
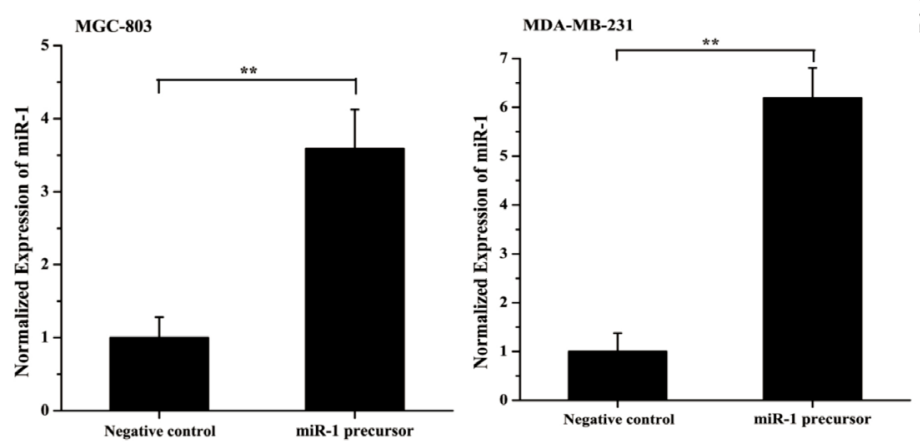

D

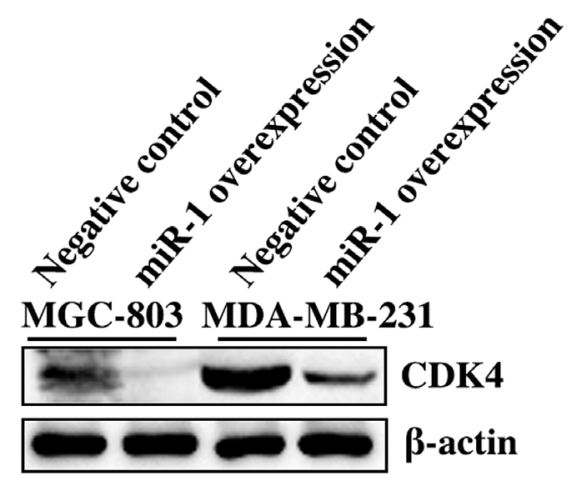

$\mathbf{E}$

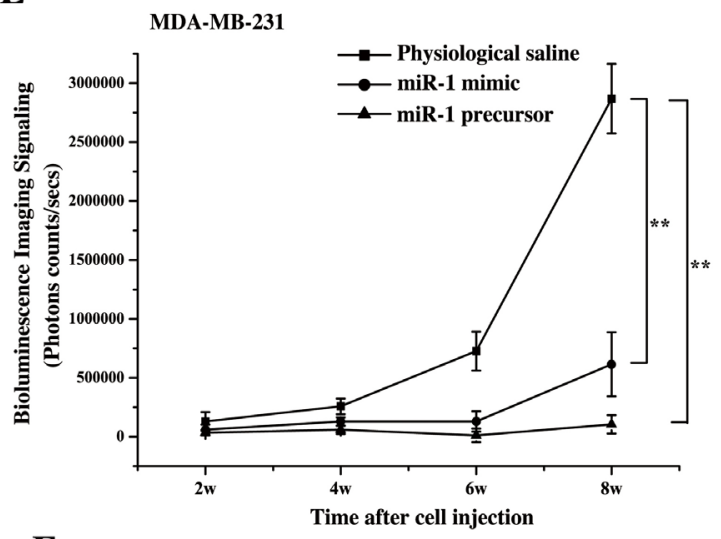

$\mathbf{F}$

MDA-MB-231

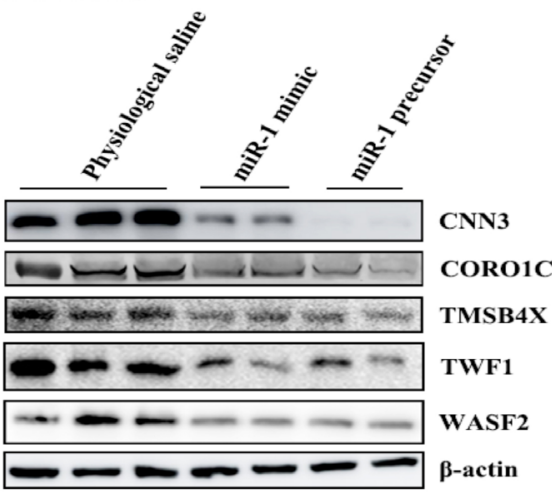

G

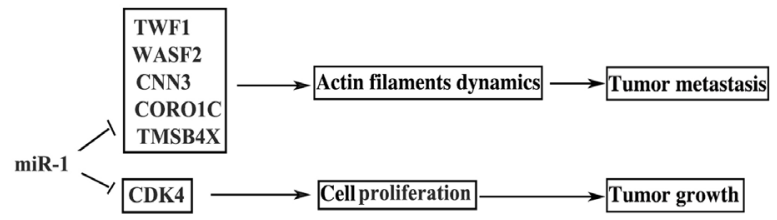

Figure 7: The miR-1-mediated tumor suppression in vivo. A. Effect of miR-1 overexpression on tumor growth in vivo. Gastric cancer cells (MGC-803) or breast cancer cells (MDA-MB-231) were transfected with the miR-1 precursor or the negative control. At 48 $\mathrm{h}$ after transfection, the cells were subcutaneously injected into nude mice. And subsequent tumor growth was examined weekly. B. The sizes of the tumors in mice. Mice were treated with miR-1-overexpressing MGC-803 cells or miR-1-overexpressing MDA-MB-231 cells. As controls, cells transfected with the negative control were also injected into mice. C. The miR-1 expression levels in tumors derived from miR-1-overexpressing MGC-803 cells or miR-1-overexpressing MDA-MB-231 cells using quantitative real-time PCR analysis. D. Western blot analysis of the miR-1 target CDK4 in tumors. E. The time course evaluation of breast cancer metastasis. The mice that received different treatments were subjected to bioluminescence imaging at various time points after the cell injection. F. The effect of miR-1 on the expression levels of its target genes in solid tumors. The solid tumors were analyzed by Western blot to detect the expression of WASF2, TWF1, CNN3, CORO1C and TMSB4X. The treatments are indicated at the top. G. Model for the miR-1-mediated inhibitory mechanism of tumor growth and metastasis. In all panels, asterisks indicate significant differences $(*, p<0.05 ; * *, p<0.01)$ between treatments. 
synthesized miR-1 (miR-1 mimic) or physiological saline was injected into the mice treated with MDA-MB-231 cells. The data revealed that metastasis of the breast cancer cells to the lungs of the mice was significantly suppressed by miR-1 mimic or miR-1 precursor compared with the negative control (Figure 7E), indicating that miR-1 could inhibit tumor metastasis. The time course assays showed that the inhibition of breast cancer metastasis appeared 3 weeks after the cell injection (Figure 7E). These findings demonstrated that miR-1 could inhibit breast cancer metastasis in vivo.

Western blot analysis of metastatic solid tumors indicated that the expression levels of miR-1 targets including WASF2, TWF1, CNN3, CORO1C and TMSB4X were significantly downregulated in the solid tumors of miR-1-overexpressing mice compared with the control mice (Figure 7F). Therefore, miR-1 could suppress cancer metastasis in vivo by downregulating target gene expression.

Taken together, these findings showed that miR1 could efficiently inhibit tumorigenesis and metastasis in vivo by targeting CDK4, WASF2, TWF1, CNN3, CORO1C and TMSB4X (Figure 7G).

\section{DISCUSSION}

The development of cancer is a complex multistep process. To date, many studies have focused on this process to inhibit tumor growth and to block cancer cell metastatic dissemination. MiRNAs, as oncogenes or tumor suppressors, play negative or positive roles in cancer development by inhibiting the expressions of genes related to tumorigenesis or metastatic dissemination [24]. The aim of our study was to explore the underlying mechanism of miRNA-mediated simultaneous suppression of both tumor growth and metastasis during cancer development. In the present investigation, miR-1 was shown to simultaneously inhibit tumor growth and metastasis of breast and gastric cancers by synchronously targeting $C D K 4$ and TMSB $4 X$, $C N N 3, T W F 1, C O R O 1 C$ and $W A S F 2$ genes. Therefore, our study identified a novel mechanism of simultaneous inhibition of tumor growth and metastasis mediated by a miRNA (miR-1).

As well known, CDK4 is required for the cell cycle transition from the G1 phase into the $\mathrm{S}$ phase. The downregulation of $C D K 4$ expression mediated by miR1 caused tumor cell cycle arrest in the G0/G1 phase, resulting in inhibited cancer cell proliferation. On the other hand, the findings of this study revealed that $T M S B 4 X$, CNN3, TWF1, CORO1C and WASF2 genes were directly targeted by miR-1. The TMSB $4 X, C N N 3, T W F 1, C O R O 1 C$ and $W A S F 2$ genes encode cytoskeletal proteins related to actin filament dynamic regulation, and they are involved in cancer metastasis [22, 25-35]. The human breast tumor biomarker miR-30c can inhibit tumor invasion by targeting the cytoskeletal network genes encoding TWF1 and vimentin [25]. As previously reported, miR-146a suppressed the migration and invasion of gastric cancer cells by targeting WASF2 [29]. In colorectal cancer, the expression of CNN3 is significantly increased and is a marker for the detection of lymph node metastasis [31]. It is reported that miR-206 represses the migration of breast cancer cells via the post-transcriptional regulation of CORO1C [33]. Recent studies have shown that TMSB4X promotes metastasis in malignant tumors. In this context, the miR-1-mediated downregulation of the TMSB $4 X$, CNN3, TWF1, CORO1C and WASF2 genes led to the inhibition of tumor cell metastasis of breast and gastric cancers.

Generally, a single miRNA can target multiple genes [14]. Thus, miRNAs can influence tumorigenesis or tumor metastasis by inhibiting the expression of one or several targets. For example, miRNA-122 inhibits the tumorigenic properties of hepatocellular carcinoma cells by repressing ADAM10 (a disintegrin and metalloprotease family 10), SRF (serum response factor), and Igf1R (insulin-like growth factor 1 receptor), which promote tumorigenesis [37]. However, no direct evidence has shown that miR-122 simultaneously interacts with its targets in cells. To date, whether a single miRNA synchronously targeted multiple genes in cells has not been addressed. In the present study, we showed that miR-1 could simultaneously cleave six targets in vitro and that miR-1 was co-localized with its targets in cells. Therefore, our study presented direct evidence that a single miRNA could simultaneously target various genes indeed.

In this investigation, miR-1 was shown to be significantly downregulated in gastric and breast cancer cells compared with normal cells. Previous studies have shown that miR-1 expression is decreased in several types of cancers, such as prostate cancer [38-40], lung cancer [41], bladder cancer [42, 43], hepatocellular carcinogenesis [44], head and neck squamous cell carcinoma [45] and thyroid carcinogenesis [46]. Our results are consistent with these previous findings. Based on the results of our studies and those of previous studies, miR-1 could serve as a biomarker for the clinical diagnosis of tumors and the restoration of miR-1 in cancers might be a potential therapeutic strategy for cancer. These issues merit further investigation.

\section{MATERIALS AND METHODS}

\section{Cell culture}

Human gastric cancer cell lines (MGC-803, MKN45, MKN74 and AGS) and a human epitheliumderived, normal gastric cell line (GES-1) were cultured in RPMI 1640 medium (Gibco, USA) supplemented with $10 \%$ fetal bovine serum (FBS). Human gastric cancer HGC-27 cells, human skin cancer A375 cells, human normal skin CCC-ESF cells and human MCF-7 breast 
cancer cells were maintained in DMEM (Gibco, USA) supplemented with $10 \%$ FBS. Human breast cancer cells, including MDA-MB-435, MDA-MB-468 and MDAMB-231 cells, were cultured in Leibovitz's L-15 medium (Gibco, USA) supplemented with 10\% FBS. Normal human MCF-10A breast cells were cultured in DMEM/ F12 (Gibco, USA) supplemented with 5\% horse serum, $10 \mu \mathrm{g} / \mathrm{ml}$ insulin, $20 \mathrm{ng} / \mathrm{ml} \mathrm{EGF}, 100 \mathrm{ng} / \mathrm{ml}$ cholera toxin and $0.5 \mu \mathrm{g} / \mathrm{ml}$ hydrocortisone. All cells were cultured in a humidified atmosphere of $5 \% \mathrm{CO}_{2}$ and $95 \%$ air at $37{ }^{\circ} \mathrm{C}$. All cells were purchased from The Type Culture Collection of The Chinese Academy of Sciences, Shanghai, China.

\section{Quantitative real-time PCR for the quantification of miR-1}

To detect the expression of miR-1, total RNA was extracted from cells and tissues with a mirVana miRNA Isolation Kit (Ambion, USA). After treatment with DNase I, the cDNA was reverse transcribed from the total RNA using an miRNA-specific primer with a TaqMan ${ }^{\circledR}$ microRNA reverse transcription kit (Applied Biosystems, USA). The real-time PCR reaction mixture $(10 \mu \mathrm{l})$ contained $0.5 \mu \mathrm{l}$ of RT product, $5 \mu \mathrm{l}$ of TaqMan 2×Universal PCR Master Mix (Applied Biosystems) and $1 \mu \mathrm{l}$ of TaqMan miRNA Assay reagent (Applied Biosystems). Real-time PCR was performed at $95^{\circ} \mathrm{C}$ for $10 \mathrm{~min}$, followed by 50 cycles at $95^{\circ} \mathrm{C}$ for $15 \mathrm{~s}$ and $60^{\circ} \mathrm{C}$ for $1 \mathrm{~min}$. The $2^{-(\Delta \Delta \mathrm{Ct})}$ method [42] was used to determine relative individual miRNA quantities, and U6 (Applied Biosystems) was used as an internal standard for normalization. The assays were performed in triplicate.

\section{Pathological analysis of gastric cancer patients}

After the gastric cancer patients were examined by gastroscopy, paired normal and cancerous tissue samples were resected from each patient. Tissue samples were fixed in $10 \%$ buffered formalin for $12 \mathrm{~h}$; and were then washed with phosphate-buffered saline (PBS). Subsequently, the samples were transferred to $70 \%$ ethanol, embedded in paraffin and sectioned. After being stained with hematoxylin and eosin, the samples were examined with white light microscopy and polarized light microscopy.

\section{Gastric sample preparation}

The resected cancerous tissues and adjacent normal tissues were immediately immersed in RNAlater solution (Ambion, USA), kept overnight, and then stored at $-80^{\circ} \mathrm{C}$ for later use.

\section{Overexpression of miR-1 in cells}

Cells were transfected with $30 \mathrm{nM}$ of the miR-1 precursor (Ambion, USA) or the negative control miRNA
(Ambion, USA) using Lipofectamine ${ }^{\circledR}$ RNAiMAX (Life Technologies, USA). At $48 \mathrm{~h}$ after transfection, total RNA was extracted with a mirVana miRNA Isolation Kit (Ambion, USA), followed by treatment with DNase I (Tiangen, Shanghai, China). The cDNAs were reverse transcribed from the total RNA using an miRNA-specific primer with a TaqMan $\AA$ microRNA reverse transcription kit (Applied Biosystems, USA). Then, real-time PCR was conducted at $95{ }^{\circ} \mathrm{C}$ for $10 \mathrm{~min}$, followed by 50 cycles at $95^{\circ} \mathrm{C}$ for $15 \mathrm{~s}$ and $60{ }^{\circ} \mathrm{C}$ for $1 \mathrm{~min}$. The real-time PCR reaction mixture $(10 \mu \mathrm{l})$ contained $0.5 \mu \mathrm{l}$ of reverse transcription product, $5 \mu \mathrm{l}$ of TaqMan $2 \times$ Universal PCR Master Mix (Applied Biosystems, USA), and $1 \mu$ l of TaqMan miRNA Assay reagent (Applied Biosystems, USA). The expression of miR-1 was normalized to U6 (Applied Biosystems, USA). All reactions were performed in triplicate.

\section{Cell proliferation assay}

Cells were plated in 96-well plates, incubated overnight, and then transfected with $30 \mathrm{nM}$ of the miR-1 precursor or the negative control miRNA (Ambion, USA) using Lipofectamine ${ }^{\circledR}$ RNAiMAX (Life Technologies, USA). Cell proliferation was monitored every $24 \mathrm{~h}$ for 5 days using a CellTiter $96 \AA$ AQueous One Solution Cell Proliferation Assay Kit (Promega, USA) according to the manufacturer's protocol. To measure cell proliferation, 20 $\mu$ of CellTiter $96 \AA$ AQueous One Solution Reagent was added to each well, and the plates were incubated at $37^{\circ} \mathrm{C}$ for $3 \mathrm{~h}$. Absorbance was measured at $490 \mathrm{~nm}$ using the iMARK $^{\mathrm{TM}}$ microplate reader (Bio-Rad, USA).

\section{Cell cycle assay}

Fluorescence-activated cell sorting (FACS) analysis was used to examine the cell cycle of gastric cancer and normal cells. The cancer cells (MGC-803, HGC-27 and MKN45) and normal cells (GES-1) were transfected with $30 \mathrm{nM}$ of the miR-1 precursor or the negative control miRNA (Ambion, USA). At $48 \mathrm{~h}$ after transfection, the cells were collected and fixed with $70 \%$ ethanol overnight at $4{ }^{\circ} \mathrm{C}$. Then, the cells were centrifuged at $300 \times g$ for $10 \mathrm{~min}$. After being washed with PBS, the cells were stained with propidium iodide solution [20 $\mu \mathrm{g} / \mathrm{ml}$ of propidium iodide (Sigma, USA), and, $200 \mu \mathrm{g}$ / $\mathrm{mL}$ of RNaseA (Sangon, China)] for $30 \mathrm{~min}$ at $37^{\circ} \mathrm{C}$ in the dark. Subsequently the cells were examined using FACS-Calibur flow cytometer (BD Biosciences, USA). Flow cytometric data were analyzed using Cell Quest Pro software (BD Biosciences, USA).

\section{Detection of cell senescence}

Senescence was analyzed using a senescence $\beta$-galactosidase staining kit (Beyotime Institute of Biotechnology, Shanghai, China). Cells were transfected 
with the miR-1 precursor or the negative control miRNA. At $48 \mathrm{~h}$ after transfection, the cells were collected and fixed with fixing solution (Beyotime, China) for 15 min. The cells were stained with senescence-associated $\beta$-galactosidase staining solution (Beyotime, China) overnight at $37^{\circ} \mathrm{C}$.

\section{Western blot analysis}

Cells transfected with the precursor miR-1 or the negative control miRNA were collected by centrifugation at $300 \times g$ for $10 \mathrm{~min}$ and were then lysed using radio immunoprecipitation assay buffer (Beyotime, China) containing $2 \mathrm{mM}$ phenylmethanesulfonyl fluoride (PMSF). The proteins were separated by SDS-PAGE and electrotransferred to polyvinylidene fluoride membranes (Millipore, USA). After being incubated in blocking solution $[4 \%$ bovine serum albumin (BSA) in TBST (Trisbuffered saline and Tween-20)] for $2 \mathrm{~h}$ at temperature, the membranes were incubated with primary antibodies overnight at $4{ }^{\circ} \mathrm{C}$. Subsequently, the membranes were incubated with AP-conjugated secondary antibodies (Roche, USA) for $2 \mathrm{~h}$ at room temperature. After being washed with TBST, the membranes were then incubated with BCIP/NBT substrate (Sangon, China) until the blots were visualized. The antibodies used in this study were purchased (Abcam, USA).

\section{Apoptosis assay}

Cells transfected with the miR-1 precursor or the negative control miRNA were collected $48 \mathrm{~h}$ after transfection by centrifugation at $300 \times g$ for $10 \mathrm{~min}$. After being washed with cold PBS, the cells were stained with FITC-AnnexinV and propidium iodide using a FITC Annexin V apoptosis detection kit (BD Biosciences, USA) according to the manufacturer's recommendations and were immediately analyzed by flow cytometry (BD Biosciences, USA). Flow cytometric data were analyzed using Cell QuestPro software (BD Biosciences, USA). Cells were divided into viable cells, dead cells, early apoptotic cells, and apoptotic cells and the percentages of apoptotic cells were calculated. All the experiments were conducted in triplicate.

\section{Prediction of miR-1 target genes}

The putative target genes of miR-1 were predicted using the miRanda, TargetScan and PicTar algorithms (Creighton et al, 2008; Doran and Strauss, 2007; Krek et al, 2005). The overlapping target genes were further investigated.

\section{Quantitative real-time PCR analysis of mRNA}

Cells were transfected with $30 \mathrm{nM}$ of the miR1 precursor or the negative control for miR-1 (Ambion,
USA). At $24 \mathrm{~h}$ after transfection, the cells were collected, and total RNA was extracted with an RNAprep pure Tissue Kit (Tiangen, China). First-strand cDNA was synthesized by reverse transcription with a PrimeScript 1st Strand cDNA Synthesis Kit (TaKaRa, Japan). Quantitative real-time PCR was conducted with gene-specific primers. The reaction mix consisted of $10 \mu$ of SYBR Green PCR Master Mix (TaKaRa, Japan), $0.4 \mu$ of $10 \mu \mathrm{M}$ forward and reverse primers and $0.5 \mu \mathrm{l}$ of cDNA in a final volume of 20 $\mu 1$. The PCR conditions were $30 \mathrm{~s}$ at $95^{\circ} \mathrm{C}$, followed by 40 cycles of $95{ }^{\circ} \mathrm{C}$ for $5 \mathrm{~s}$ and $60^{\circ} \mathrm{C}$ for $30 \mathrm{~s}$. The expression levels of genes were normalized to glyceraldehyde-3phosphate dehydrogenase (GAPDH).

\section{Dual-luciferase reporter assay}

The 3'UTR of CDK4, TMSB4X, TWF1, CNN3, $W A S F 2$ or $C O R O 1 C$ was amplified with sequence-specific primers (CDK4, 5'-CATTTC CCTTCTGGACACT G-3' and 5'-GCCTCAGTCTCCCAAGTAGC-3'; TMS B4X, 5'-TGCGCCGCCAAT ATGCACTGTAC-3' and 5'-CCTGCCAGCCAGATAGATAGAC-3'; TWF1, 5'-TT CCATGGGTGTACACGTAGA-3' and 5'-ATGTCCAC CAGAAGGCATGTAA-3'; CNN3, 5'-ATCCACACAG AAGGAGCTCAGT-3' and 5'-CAAATGCATCACCCA GGCCTA-3'; WASF2, 5'-CTTTAGACCCAGAGCC CTTTAAGA-3' and 5'-AGAG ACCTCAATCTGT CCAAGCT-3'; CORO1C， 5'-AGCTGGTTATTGGTG TGGTCC TA-3' and 5'-ATGAGAGCGGTGGTAATATG AATC-3'). Then, it was cloned into the pmirGLO dualluciferase miRNA target expression vector (Promega, USA). As a control, the seed sequence of $3^{\prime}$ UTR of the CDK4, TMSB4X, TWF1, CNN3, WASF2 or CORO1C was randomly mutated and cloned into pmirGLO dual-luciferase miRNA target expression vector, generating CDK4-3'UTR-mutant, TMSB4X-3'UTRmutant, TWF1-3'UTR-mutant, CNN3-3'UTR-mutant, WASF2-3'UTR-mutant or CORO1C-3'UTR-mutant, respectively. The primers used for the amplifications of the 3'-UTR mutants were sequence-specific (CDK4, 5'-AGAGGTGGGAGGACATTCCCATTA AGGCAGC-3' and 5'-GCTGCCTTAATGGGAATGTCCTCCCACCT CT-3'; TMSB4X, 5'-CCAATATGCACTGTCTCGCTAAC AAGCATTGC-3' and 5'-GAAG GCAATGCTTGTTAGC GAGACAGTGCATAT-3'; TWF1, 5'-GTAAATGGCTCG CTAAGAATATAGATGTGATTA-3' and 5'-CATCTATA TTCTTAGCGAGCCATT TACTTTAATGT-3'; CNN3, 5'-TTGCCTTACGTCTCGCTATTTTTCCTTTTTCTG -3' and 5'-AAGGAAAAATAGCGAGACGTAA GGCAATTTTTC-3'; WASF2, 5'-TGAGATG GGTCTCGCTAAAAGGAGCAGCCT-3' and 5'-CTGCTCCTTTTAG CGAGACCCATCTCACAAC-3'; CORO1C, 5'-CCATTTG GAGCTCGCTAATTTC AGATTTGTC-3' and 5'-AATCT GAAATTAGCGAGCTCCAAATGGCAG-3'). 
For the dual-luciferase reporter assays, HGC-27 cells were plated in a 96-well plate, incubated overnight, and then co-transfected with the miR-1 miExpress vector (Applied Biosystems, USA) or the vector only and CDK4-3'UTR, TMSB 4X-3'UTR, TWF1-3'UTR, CNN33'UTR, WASF2-3'UTR or COROIC-3'UTR constructs using Attractene Transfection Reagent (Qiagen, USA). As controls, CDK4-3'UTR-mutant, TMSB 4X-3'UTRmutant, TWF1-3'UTR-mutant, CNN3-3'UTR-mutant, WASF2-3'UTR-mutant and COROIC-3'UTR-mutant were included in the co-transfections. At $24 \mathrm{~h}$ after transfection, the cells were collected and washed twice with PBS. Subsequently, passive lysis buffer (Promega, USA) was added to promote the rapid lysis of cells. After incubation for $15 \mathrm{~min}$ at room temperature, the lysate was used to detect luciferase activity. The luciferase activity detection was performed according to the protocol for the Dual-Luciferase Assay Reagent (Promega, USA). All the experiments were repeated for three times.

\section{Cell migration assay}

Cell migration was assessed using 24-well Boyden chambers (Costar, Corning, USA) with $8-\mu \mathrm{m}$-inserts. Cells were transfected with the miR-1 precursor or the negative control miRNA and were then incubated for $48 \mathrm{~h}$. Then, the cells were trypsinized, and $5 \times 10^{4}$ cells were resuspended in $100 \mu \mathrm{l}$ serum-free media and added to the inserts. The inserts were placed in wells with $600 \mu \mathrm{l}$ of $10 \%$ serum-containing media. After 24 $\mathrm{h}$ of incubation, the membranes of the inserts were carefully washed with cold PBS and fixed with $4 \%$ paraformaldehyde (Sigma, USA) for $15 \mathrm{~min}$, followed by staining with crystal violet $(0.005 \%$, Beyotime, China) for $15 \mathrm{~min}$. Then the cells on the upper sides of the membranes were wiped away with cotton swabs. Images of the migrated cells were collected using a Nikon Ti-S microscope (Nikon, USA). The data are shown as the numbers of migrated cells per $200 \times$ field of view for each sample well. All experiments were independently repeated three times.

\section{Confocal microscopy}

Cells were plated in glass bottomed dishes (In Vitro Scientific, USA), incubated overnight, and then transfected with $30 \mathrm{nM}$ of the miR-1 precursor or the negative control RNA for $48 \mathrm{~h}$. The transfected cells were fixed in 4\% paraformaldehyde for $15 \mathrm{~min}$. After two washes with PBS, the cells were treated with $0.25 \%$ Triton X-100 for 15 min, followed by staining with fluorescent phalloidin (R415, Invitrogen, USA) for $40 \mathrm{~min}$ and then DAPI (Sigma, USA) for $5 \mathrm{~min}$. Images of F-actin were captured using a Carl Zeiss LSM710 system (Carl Zeiss, Germany).

\section{Cell adhesion assay}

The ability of cells to adhere to fibronectin were also assessed. Cells were seeded in 24-well plates pre-coated with $20 \mu \mathrm{g} / \mathrm{ml}$ fibronectin (Sigma, USA) and incubated at $4{ }^{\circ} \mathrm{C}$ overnight. Then the plates were washed with PBS twice and were incubated with $10 \% \mathrm{BSA}$ at $37^{\circ} \mathrm{C}$ to block non-specific binding proteins. Cells $\left(5 \times 10^{4}\right)$ treated with $30 \mathrm{nM}$ of the miR-1 precursor or the negative control were resuspended in serum-free medium and transferred to the coated plates. Subsequently, the cells were allowed to adhere for $30 \mathrm{~min}$ at $37^{\circ} \mathrm{C}$. To remove non-adherent cells, the plates were washed with PBS twice. The adherent cells were then fixed with $4 \%$ paraformaldehyde and stained with a methylrosanilnium chloride solution (Beyotime, China) for $15 \mathrm{~min}$, and examined under a microscope.

\section{Cell invasion assay}

Cell invasion was assessed using 24-well Matrigel invasion chambers (Costar, Corning, USA) with $8-\mu \mathrm{m}$ inserts. Cells were transfected with $30 \mathrm{nM}$ of the miR-1 precursor or the negative control. Forty-eight hours later, the cells were trypsinized. Subsequently, the cells were resuspended in $100 \mu \mathrm{l}$ of serum-free media and added to the inserts, which were placed into wells with $600 \mu \mathrm{l}$ of $10 \%$ serum-containing media. After $24 \mathrm{~h}$ of incubation, the membranes of the inserts were carefully washed with cold PBS, fixed with 4\% paraformaldehyde (Sigma, USA) for $15 \mathrm{~min}$, and stained with crystal violet $(0.005 \%$, Beyotime, China) for $15 \mathrm{~min}$. The cells on the upper side of the membrane were removed with a cotton swab. Images of invaded cells were collected using a Nikon Ti-S microscope (Nikon, USA).

\section{miR-1-guided cleavage of miR-1 target mRNA}

A 500 -bp fragment of miR-1 target's 3'UTR was amplified with sequence-specific primers (TWF1, 5'-GATCACTAATACGACTCACTATAGG GTGCATTA TCAGTTACAACCT-3' and 5'-TGGCAC TCTGATTAAACTGCAT-3'; WASF2, 5'- GATCACTAAT ACGACTCACTATAGGGCTTTAGACCCAGAGCCCT TTAAGA- $3^{\prime}$ and 5'-AGAGACCTCAATCTGTCCAA GCT-3'; TMSB4X, 5'-GATCACTAAT ACGACTCA CTATAGGGTGCGCCGCCAATATGCACTGT- $3^{\prime}$ and 5'-TGGCACT CTGATTAAACTGCAT-3'; CNN3, 5'- GATCACTAATACGACTCACTATAGG GATCCACA CAGAAGGAGCTCAGT-3' and 5'-CAAATGCATCA CCCAGGCCT A-3'; CORO1C, 5'- GATCACTAATA CGACTCACTATAGGGAGCTGGTTATT GGTGTG GTCCTA-3' and 5'-ATGAGAGCGGTGGTAATA TGAATC-3'; CDK4, 5'- GATCACTAATACGACTCACTA TAGGGCATGGAAGGAAGAAAAGCTG-3' and 5'-TTC AAGCGATCCTCCTGCCT-3'). Then, the PCR products were used as templates for target mRNA transcription in vitro with a $\mathrm{T} 7$ transcription kit (TaKaRa, Japan). 
In vitro transcription was performed according to the manufacturer's protocol.

To facilitate the miR-1-guided cleavage of target mRNA, the endogenous Ago2 complex was obtained. The cultured cells were lysed with lysis buffer $(20 \mathrm{mM}$ Tris-HCl, $150 \mathrm{mM} \mathrm{NaCl}, 1.5 \mathrm{mM} \mathrm{MgCl}{ }_{2}, 0.25 \%$ NP-40, 1 $\mathrm{mM}$ PMSF, $\mathrm{pH} 7.5$ ) for $15 \mathrm{~min}$ on ice and then centrifuged at $10,000 \times g$ for $10 \mathrm{~min}$ at $4^{\circ} \mathrm{C}$. The cell lysate was incubated with Ago 2 antibody for $1 \mathrm{~h}$ at $4^{\circ} \mathrm{C}$. Subsequently protein-G-coupled agarose beads were equilibrated with lysis buffer and incubated with the cell lysate and Ago2 antibody for $4 \mathrm{~h}$ at $4{ }^{\circ} \mathrm{C}$. Then, the beads were washed three times with wash buffer $(50 \mathrm{mM}$ Tris-HCl, $300 \mathrm{mM}$ $\mathrm{NaCl}, 5 \mathrm{mM} \mathrm{MgCl} 2,0.1 \% \mathrm{NP}-40, \mathrm{pH} 7.5)$ and suspended in cleavage reaction buffer $(100 \mathrm{mM} \mathrm{KOAc,} 40 \mathrm{mM}$ HEPES, $5 \mathrm{mM} \mathrm{MgCl}$, 2 mM DTT, 0.35\% Triton X-100, $1 \mathrm{mM}$ phenylmethanesulfonyl fluoride, $\mathrm{pH}$ 7.6).

The target mRNA (200 ng) was incubated in $20 \mu \mathrm{l}$ of reaction solution containing $10 \mu \mathrm{l}$ of Ago 2 complex, $2 \mu \mathrm{l}$ of $10 \mathrm{mM}$ ATP/2 mM GTP solution, and $10 \mathrm{U} / \mathrm{ml}$ of RNasin (Promega, USA) and miR-1 (Genepharm, China) at $37^{\circ} \mathrm{C}$. At different times after this incubation, the RNA was separated by $1 \%$ agarose gel electrophoresis and then transferred to a nylon membrane (GE Healthcare, USA). The RNA was detected using a DIG (digoxigenin)labeled probe (TWF1, 5'-TCACCATCTAGGTATGA TACTGCCAACTAA-3'; WASF1, 5'-GTTTCTGAGGGCGCTCGGGCTTCCACTG GA3'; TMSB4X, 5'-TCCTTCCCTGCCAGCCAGATAG ATAGACAG-3'; CNN3， 5'-GCAATAAGCATGAGT TTAGTCTTCCATGTAG-3'; CORO1C, 5'-GGAGCC AGCACCATGTGGCTACTGCTTTGA-3'; CDK4, 5'-TCCAAATCGCACAATGGC AAAGCCAAACAG-3').

\section{Intracellular co-localization of miR-1 and its target mRNAs}

Fluorescence in situ hybridization was conducted to intracellularly localize miR-1 and its target mRNAs. MDA-MB-435 cells were transfected with $30 \mathrm{nM}$ of the miR-1 precursor and then cultured for $48 \mathrm{~h}$. The cells were fixed with $4 \%$ polyformaldehyde for $15 \mathrm{~min}$ at room temperature. After two washes with PBS, the fixed cells were dehydrated in $70 \%$ ethanol overnight at $4{ }^{\circ} \mathrm{C}$ To label an mRNA, the cells were incubated with hybridization buffer [ $1 \times \mathrm{SSC}(15 \mathrm{mM}$ sodium citrate plus, $150 \mathrm{mM}$ sodium chloride, $\mathrm{pH} 7.5), 25 \%$ (w/v) formamide, $10 \%(\mathrm{w} / \mathrm{v})$ dextran sulfate, $1 \times$ Denhardt's solution] containing $100 \mathrm{nM}$ biotin-labeled probe for $5 \mathrm{~h}$ at $37{ }^{\circ} \mathrm{C}$. The following probes were used: TWF1 probe (5'-biotin-TGCTCGGAAGTGATAAA GAACA-3'), TMSB4X probe (5'-biotinTTCTTCCTTCACCAACATGCAA-3'), WASF2 probe (5'-biotin-ACTGAGCTAATGATCTAATCCT-3'),

CNN3 probe (5'-fluoresceinAAGAACTGGCTGTACAAGAGTA-3'), CORO1C probe (5'-fluorescein-AGGAC CACACCAATAACCAGCT-3') and CDK4 probe (5'-fluorescein-TACAGCCAACA CTCCACATGT-3'). The cells were washed with $4 \times$ SSC for $10 \mathrm{~min}, 2 \times \mathrm{SSC}$ for $5 \mathrm{~min}$ and $1 \times \mathrm{SSC}$ for $5 \mathrm{~min}$. To label miR-1, the cells were incubated with hybridization buffer containing $100 \mathrm{nM}$ DIG-labeled miR-1 probe (5'-DIG-ATACATACTTCTTTACATTCCA -3') overnight at $37^{\circ} \mathrm{C}$. After being washed with an SSC series $(4 \times \mathrm{SSC}$, $2 \times \mathrm{SSC}$ and $1 \times \mathrm{SSC}$ for 10,5 and $5 \mathrm{~min}$, respectively), the cells were treated with blocking reagent (PBST, PBS containing $1 \%$ BSA and $0.02 \%$ Tween-20) for $1 \mathrm{~h}$ at room temperature, followed by an incubation with $0.3 \% \mathrm{H}_{2} \mathrm{O}_{2}$ for $20 \mathrm{~min}$. Subsequently the cells were incubated with horseradish peroxidase (HRP) -labeled anti-DIG antibody (Roche, Switzerland) for $1 \mathrm{~h}$ at room temperature and washed with PBS three times. Amplification buffer/ $\mathrm{H}_{2} \mathrm{O}_{2}$ stock solution containing Alexa Fluor 546 tyramide (Roche, Switzerland) was added to the cells and incubated for $10 \mathrm{~min}$ at room temperature. After washing with PBS, the cells were incubated with HRP-labeled streptavidin (Roche, Switzerland) for $1 \mathrm{~h}$ at room temperature, followed by a treatment with $0.3 \% \mathrm{H}_{2} \mathrm{O}_{2}$ for $20 \mathrm{~min}$. The cells were washed three times with $\mathrm{PBS}$, and then then amplification buffer $/ \mathrm{H}_{2} \mathrm{O}_{2}$ stock solution containing Alexa Fluor 488 tyramide (Roche, Switzerland) were added. After incubating for $10 \mathrm{~min}$, the cells were washed with PBS three times. Finally, the cells were labeled with DAPI (50 ng/ml) (Sigma, USA) for $5 \mathrm{~min}$ and washed with PBS. Cell images were captured using a CarlZeiss LSM710 system (Carl Zeiss, Germany).

\section{Tumorigenicity in nude mice}

To evaluate the influence of miR-1 on cancer cell growth in vivo, the gastric cancer cells (MGC-803) or the breast cancer cells (MDA-MB-231) were transfected with $30 \mathrm{nM}$ of the miR-1 precursor or the scrambled miRNA (negative control) when the cell density reached approximately $50 \%$. At $48 \mathrm{~h}$ after transfection, cells $\left(1 \times 10^{6}\right)$ were subcutaneously injected into non-obese diabetic severe combined immunodeficiency (NOD/SCID) mice to induce tumor growth. The tumor volumes were measured weekly. Five weeks (MGC-803) or eight weeks later (MDA-MB-231), the NOD/SCID nude mice were euthanized and their tumor sizes were evaluated.

To examine the effects of miR-1 on cancer cell metastasis in vivo, the animal model of breast cancer cell metastasis to lung was established as described previously with some modifications [6, 13, 19]. Luciferase expressing MDA-MB-231 cells were constructed by lentiviral packaging to analyze tumor metastasis in vivo. Then, MDA-MB-231 cells were transfected with $30 \mathrm{nM}$ of the miR-1 precursor. At $48 \mathrm{~h}$ after transfection, cells $\left(2 \times 10^{5}\right)$ transfected with the miR-1 precursor or control cells $\left(2 \times 10^{5}\right)$ were intravenously injected via the tail vein into nude mice. Every 3 days after the injection, the mice were intravenously injected via the tail vein with $200 \mathrm{nM}$ of synthesized miR-1 or physiological saline. 
The metastatic tumors were imaged weekly using an IVIS Spectrum CT Preclinical In Vivo Imaging System (PerkinElmer, USA). At 8 weeks after the cell injection, the mice were euthanized and the tumors in the lungs were excised for later use. The animal experiments were approved by The Animal Experiment Center of Zhejiang University, China.

\section{Authors' contribution}

Xiaobo Zhang and Cuilian Liu designed experiments; Cuilian Liu, Song Zhang and Qizhi Wang performed experiments; Cuilian Liu and Xiaobo Zhang analysed data and wrote the paper.

\section{CONFLICTS OF INTEREST}

The authors declare no conflicts of interest.

\section{FUNDING}

This work was financially supported by National Natural Science Foundation of China (31430089) and the National Basic Research Program of China (2015CB755903).

\section{REFERENCES}

1. Jemal A, Bray F, Center MM, Ferlay J, Ward E, Forman D. Global cancer statistics. CA Cancer J Clin. 2011; 61: 69-90.

2. Heinemann V, Douillard JY, Ducreux M, Peeters M. Targeted therapy in metastatic colorectal cancer--an example of personalised medicine in action. Cancer Treat Rev. 2013; 39: 592-601.

3. Winter J, Jung S, Keller S, Gregory RI, Diederichs S. Many roads to maturity: microRNA biogenesis pathways and their regulation. Nat Cell Biol. 2009; 11: 228-234.

4. Song YX, Yue ZY, Wang ZN, Xu YY, Luo Y, Xu HM, Zhang X, Jiang L, Xing CZ, Zhang Y. MicroRNA-148b is frequently down-regulated in gastric cancer and acts as a tumor suppressor by inhibiting cell proliferation. Mol Cancer. 2011; 10: 1 .

5. Gibbons DL, Lin W, Creighton CJ, Rizvi ZH, Gregory PA, Goodall GJ, Thilaganathan N, Du L, Zhang Y, Pertsemlidis A, Kurie JM. Contextual extracellular cues promote tumor cell EMT and metastasis by regulating miR-200 family expression. Genes Dev. 2009; 23: 2140-2151.

6. Korpal M, Ell BJ, Buffa FM, Ibrahim T, Blanco MA, CeliaTerrassa T, Mercatali L, Khan Z, Goodarzi H, Hua Y, Wei Y, Hu G, Garcia BA, et al. Direct targeting of Sec23a by miR-200s influences cancer cell secretome and promotes metastatic colonization. Nat Med. 2011; 17: 1101-1108.

7. Pan X, Wang ZX, Wang R. MicroRNA-21: a novel therapeutic target in human cancer. Cancer Biol Ther. 2010; 10: $1224-1232$.
8. Brennecke J, Stark A, Russell RB, Cohen SM. Principles of microRNA-target recognition. PLoS Biol. 2005; 3: e85.

9. Lewis BP, Burge CB, Bartel DP. Conserved seed pairing, often flanked by adenosines, indicates that thousands of human genes are microRNA targets. Cell. 2005; 120: 15-20.

10. Liu Q, Fu H, Sun F, Zhang H, Tie Y, Zhu J, Xing R, Sun Z, Zheng X. miR-16 family induces cell cycle arrest by regulating multiple cell cycle genes. Nucleic Acids Res. 2008; 36: 5391-5404.

11. Sun A, Bagella L, Tutton S, Romano G, Giordano A. From G0 to $S$ phase: a view of the roles played by the retinoblastoma $(\mathrm{Rb})$ family members in the $\mathrm{Rb}-\mathrm{E} 2 \mathrm{~F}$ pathway. J Cell Biochem. 2007; 102: 1400-1404.

12. Hallstrom TC, Nevins JR. Balancing the decision of cell proliferation and cell fate. Cell Cycle. 2009; 8: 532-535.

13. Patsialou A, Wang Y, Lin J, Whitney K, Goswami S, Kenny PA, Condeelis JS. Selective gene-expression profiling of migratory tumor cells in vivo predicts clinical outcome in breast cancer patients. Breast Cancer Res. 2012; 14: R139.

14. Luan SL, Boulanger E, Ye H, Chanudet E, Johnson N, Hamoudi RA, Bacon CM, Liu H, Huang Y, Said J, Chu P, Clemen CS, Cesarman E, et al. Primary effusion lymphoma: genomic profiling revealed amplification of SELPLG and CORO1C encoding for proteins important for cell migration. J Pathol. 2010; 222: 166-179.

15. Gauger KJ, Hugh JM, Troester MA, Schneider SS. Down-regulation of sfrp1 in a mammary epithelial cell line promotes the development of a cd44high/cd24low population which is invasive and resistant to anoikis. Cancer Cell Int. 2009; 9: 11.

16. Meacham CE, Ho EE, Dubrovsky E, Gertler FB, Hemann MT. In vivo RNAi screening identifies regulators of actin dynamics as key determinants of lymphoma progression. Nat Genet. 2009; 41: 1133-1137.

17. Wirtz D, Konstantopoulos K, Searson PC. The physics of cancer: the role of physical interactions and mechanical forces in metastasis. Nat Rev Cancer. 2011; 11: 512-522.

18. Calin GA, Croce CM. MicroRNA-cancer connection: the beginning of a new tale. Cancer Res. 2006; 66: 7390-7394.

19. Bockhorn J, Yee K, Chang YF, Prat A, Huo D, Nwachukwu C, Dalton R, Huang S, Swanson KE, Perou CM, Olopade OI, Clarke MF, Greene GL, Liu H. MicroRNA-30c targets cytoskeleton genes involved in breast cancer cell invasion. Breast Cancer Res Treat. 2013; 137: 373-382.

20. Takenawa T, Miki H. WASP and WAVE family proteins: key molecules for rapid rearrangement of cortical actin filaments and cell movement. J Cell Sci. 2001; 114: 1801-1809.

21. Kurisu S, Suetsugu S, Yamazaki D, Yamaguchi H, Takenawa T. Rac-WAVE2 signaling is involved in the invasive and metastatic phenotypes of murine melanoma cells. Oncogene. 2005; 24: 1309-1319.

22. Yang LY, Tao YM, Ou DP, Wang W, Chang ZG, Wu F. Increased expression of Wiskott-Aldrich syndrome protein 
family verprolin-homologous protein 2 correlated with poor prognosis of hepatocellular carcinoma. Clin Cancer Res. 2006; 12: 5673-5679.

23. Yao Q, Cao Z, Tu C, Zhao Y, Liu H, Zhang S. MicroRNA$146 \mathrm{a}$ acts as a metastasis suppressor in gastric cancer by targeting WASF2. Cancer Lett. 2013; 335: 219-224.

24. Shibukawa Y, Yamazaki N, Kumasawa K, Daimon E, Tajiri M, Okada Y, Ikawa M, Wada Y. Calponin 3 regulates actin cytoskeleton rearrangement in trophoblastic cell fusion. Mol Biol Cell. 2010; 21: 3973-3984.

25. Nakarai C, Osawa K, Akiyama M, Matsubara N, Ikeuchi H, Yamano T, Hirota S, Tomita N, Usami M, Kido Y. Expression of AKR1C3 and CNN3 as markers for detection of lymph node metastases in colorectal cancer. Clin Exp Med. 2015; 15: 333-341.

26. Roadcap DW, Clemen CS, Bear JE. The Role of Mammalian Coronins in Development and Disease. The Coronin Family of Proteins. 2008; 48:124-135.

27. Wang J, Tsouko E, Jonsson P, Bergh J, Hartman J, Aydogdu E, Williams C. miR-206 inhibits cell migration through direct targeting of the actin-binding protein Coronin $1 \mathrm{C}$ in triple-negative breast cancer. Mol Oncol. 2014; 8: 1690-1702.

28. Cha HJ, Jeong MJ, Kleinman HK. Role of thymosin $\beta 4$ in tumor metastasis and angiogenesis. J Natl Cancer Inst. 2003; 95: 1674-1680.

29. Kobayashi T, Okada F, Fujii N, Tomita N, Ito S, Tazawa H, Aoyama T, Choi SK, Shibata T, Fujita H, Hosokawa M. Thymosin- $\beta 4$ regulates motility and metastasis of malignant mouse fibrosarcoma cells. Am J Pathol. 2002; 160: 869-882.

30. Jiang S, Zhao C, Yang X, Li X, Pan Q, Huang H, Wen X, Shan H, Li Q, Du Y, Zhao Y. miR-1 suppresses the growth of esophageal squamous cell carcinoma in vivo and in vitro through the downregulation of MET, cyclin D1 and CDK4 expression. Int J Mol Med. 2016; 38: 113-122.

31. Mataki H, Enokida H, Chiyomaru T, Mizuno K, Matsushita R, Goto Y, Nishikawa R, Higashimoto I, Samukawa T, Nakagawa M, Inoue H, Seki N. Downregulation of the microRNA-1/133a cluster enhances cancer cell migration and invasion in lung-squamous cell carcinoma via regulation of Coronin1C. J Hum Genet. 2015; 60: 53-61.

32. Bai S, Nasser MW, Wang B, Hsu SH, Datta J, Kutay H, Yadav A, Nuovo G, Kumar P, Ghoshal K. MicroRNA-122 inhibits tumorigenic properties of hepatocellular carcinoma cells and sensitizes these cells to sorafenib. J Biol Chem. 2009; 284: 32015-32027.

33. Hudson RS, Yi M, Esposito D, Watkins SK, Hurwitz AA, Yfantis HG, Lee DH, Borin JF, Naslund MJ, Alexander RB, Dorsey TH, Stephens RM, Croce CM, Ambs S. MicroRNA-1 is a candidate tumor suppressor and prognostic marker in human prostate cancer. Nucleic Acids Res. 2012; 40: 3689-3703.

34. Kojima S, Chiyomaru T, Kawakami K, Yoshino H, Enokida H, Nohata N, Fuse M, Ichikawa T, Naya Y, Nakagawa M, Seki N. Tumour suppressors miR-1 and miR-133a target the oncogenic function of purine nucleoside phosphorylase (PNP) in prostate cancer. Br J Cancer. 2012; 106: 405-413.

35. Ambs S, Prueitt RL, Yi M, Hudson RS, Howe TM, Petrocca F, Wallace TA, Liu CG, Volinia S, Calin GA, Yfantis HG, Stephens RM, Croce CM. Genomic profiling of microRNA and messenger RNA reveals deregulated microRNA expression in prostate cancer. Cancer Res. 2008; 68: 6162-6170.

36. Nasser MW, Datta J, Nuovo G, Kutay H, Motiwala T, Majumder S, Wang B, Suster S, Jacob ST, Ghoshal K. Down-regulation of micro-RNA-1 (miR-1) in lung cancer suppression of tumorigenic property of lung cancer cells and their sensitization to doxorubicin-induced apoptosis by miR-1. J Biol Chem. 2008; 283: 33394-33405.

37. Yoshino H, Chiyomaru T, Enokida H, Kawakami K, Tatarano S, Nishiyama K, Nohata N, Seki N, Nakagawa M. The tumour-suppressive function of miR-1 and miR-133a targeting TAGLN2 in bladder cancer. Br J Cancer. 2011; 104: 808-818.

38. Yoshino H, Enokida H, Chiyomaru T, Tatarano S, Hidaka H, Yamasaki T, Gotannda T, Tachiwada T, Nohata N, Yamane T, Seki N, Nakagawa M. Tumor suppressive microRNA-1 mediated novel apoptosis pathways through direct inhibition of splicing factor serine/arginine-rich 9 (SRSF9/SRp30c) in bladder cancer. Biochem Biophys Res Commun. 2012; 417: 588-593.

39. Datta J, Kutay H, Nasser MW, Nuovo GJ, Wang B, Majumder S, Liu CG, Volinia S, Croce CM, Schmittgen TD, Ghoshal K, Jacob ST. Methylation mediated silencing of microRNA-1 gene and its role in hepatocellular carcinogenesis. Cancer Res. 2008; 68: 5049-5058.

40. Nohata N, Sone Y, Hanazawa T, Fuse M, Kikkawa N, Yoshino H, Chiyomaru T, Kawakami K, Enokida H, Nakagawa M, Shozu M, Okamoto Y, Seki N. miR-1 as a tumor suppressive microRNA targeting TAGLN2 in head and neck squamous cell carcinoma. Oncotarget. 2011; 2: 29-42. doi: 10.18632/oncotarget.213.

41. Leone V, D'Angelo D, Rubio I, de Freitas PM, Federico A, Colamaio M, Pallante P, Medeiros-Neto G, Fusco A. MiR-1 is a tumor suppressor in thyroid carcinogenesis targeting CCND2, CXCR4, and SDF-1 $\alpha$. J Clin Endocrinol Metab. 2011; 96: E1388-E1398.

42. Gong Y, He T, Yang L, Yang G, Chen Y, Zhang X. The role of miR-100 in regulating apoptosis of breast cancer cells. Sci Rep. 2015; 5: 11650. 